Mélanges

de l'École française de Rome

Moyen Âge

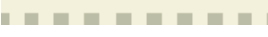

\section{Mélanges de l'École française de Rome - Moyen Âge}

133-1 | 2021

Reimpiego, rilavorazione, rifunzionalizzazione: la "lunga vita" della scultura medievale nei cantieri di Età moderna - Varia

\title{
Les Collecta ex distinctionibus Prepositini
}

Présentation et édition

\section{Marjorie Burghart}

\section{OpenEdition}

Journals

Édition électronique

URL : https://journals.openedition.org/mefrm/8703

DOI : $10.4000 /$ mefrm. 8703

ISSN : $1724-2150$

Éditeur

École française de Rome

Édition imprimée

Date de publication : 1 juin 2021

Pagination : 169-198

ISBN : 978-2-7283-1487-4

ISSN : 1123-9883

Ce document vous est offert par Centre national de la recherche scientifique (CNRS)

\section{cnrs}

Référence électronique

Marjorie Burghart, "Les Collecta ex distinctionibus Prepositini », Mélanges de l'École française de Rome Moyen Âge [En ligne], 133-1 | 2021, mis en ligne le 01 juin 2021, consulté le 29 juin 2021. URL : http:// journals.openedition.org/mefrm/8703; DOI : https://doi.org/10.4000/mefrm.8703 


\title{
Les Collecta ex distinctionibus Prepositini Présentation et édition
}

\author{
Marjorie BurghART
}

\begin{abstract}
M. Burghart, CNRS - UMR 5648 (CIHAM), marjorie.burghart@gmail.com
Cet article offre la présentation et l'édition d'une collection de distinctiones représentées de manière schématique. Transmise par un seul manuscrit connu dont nous proposons la description détaillée (Munich, Bayerische Staatsbibliothek, clm 4784), elle a un temps été attribuée à Prévostin de Crémone († 1210). Nous montrons ici que la collection date en fait probablement de la fin XIV - début $X^{\text {e }}$ siècle, tout en réinterprétant au moins en partie un fonds de distinctions de la fin XII ${ }^{e}$ - début XIII ${ }^{e}$. Elle offre donc un exemple de la persistance et des adaptations des schémas de représentation du monde véhiculés par les distinctions.
\end{abstract}

Distinctiones, prédication, Prévostin de Crémone

This article offers the introduction to and edition of a collection of distinctiones represented in a schematic manner. Known by a single manuscript that we will describe in detail (Munich, Bayerische Staatsbibliothek, clm 4784) the collection had previously been ascribed to Praepositinus Cremonensis († 1210). This study will show that the collection probably dates from the late fourteenth/early fifteenth century, whilst at the same time reinterpreting at least in part distinctions from the late twelfth/early thirteenth century. The collection therefore offers an example of the persistence and adaptation of the mental schemas for the representation of the world transmitted by the distinctions

Distinctiones, preaching, Praepositinus Cremonensis

Dans le contexte de la prédication, une distinctio consiste en une énumération plus ou moins organisée des différentes acceptions d'un mot ou d'une notion, en appuyant généralement chacune par l'autorité d'une ou plusieurs citations bibliques. Utilisées pour l'exégèse dans les écoles dès le $\mathrm{XII}^{\mathrm{e}}$ siècle, les distinctiones ont très vite été adoptées par les prédicateurs. Elles ont en particulier pris une place de plus en plus éminente avec l'avènement du sermo modernus au début du XIII ${ }^{\mathrm{e}}$ siècle $^{1}$ : dans ce nouveau style de sermon, contrairement à l'homélie, la structuration du discours a pris une place prépondérante, jusqu'à devenir un critère majeur pour juger la beauté d'un texte et le talent d'un prédicateur. ${ }^{2}$ Tout comme un autre ingré-

1. Sur le sermo modernus, voir en particulier Bériou 1998.

2. Sur la technique de la distinctio, son émergence dans la prédication et l'intérêt de son étude, v. Burghart à paraître. dient majeur des sermons de l'époque, les exempla, les distinctiones ont été rassemblées en collections destinées principalement aux prédicateurs.

Les Collecta ex distinctionibus Prepositini appartiennent à ce genre, mais présentent plusieurs particularités. Elles sont tout d'abord connues par un témoin unique, et surtout la représentation de chacune des 119 distinctions ${ }^{3}$ est figurée schématiquement, les différents sens étant regroupés par des accolades ou des traits à l'encre rouge. Ces représentations figurées, assez communes dans les marges des manuscrits de sermons notamment,

3. Lacombe 1927 donne un chiffre de 114 distinctions, qui doit être corrigé en 119 au vu de l'édition ci-après. Dans le tableau qu'il donne p. 122-124, certaines distinctions sont manquantes (reverentie signum, ordo diligendi, Christus sedet, vinum, venti et Maria Virgo), tandis que certaines entrées sont dupliquées (pour ignis ou mors, notamment) ou indûment ajoutées (virtus). 
où des lecteurs soucieux de bien mémoriser une distinction prenaient soin de la représenter de manière condensée, sont cependant plus rares dans les collections de distinctions. Enfin, les Collecta ex distinctionibus Prepositini ont pour particularité d'avoir été considérées comme l'extrait d'une œuvre de Prévostin de Crémone († 1210 $)^{4}$.

Les Collecta ex distinctionibus Prepositini tirent leur nom d'un titre ajouté en marge supérieure de leur unique témoin - titre repris dans la table des matières médiévale en tête du manuscrit. Celui-ci est aujourd'hui conservé à la Bayerische Staatsbibliothek de Munich sous la cote clm 4784, et une copie numérique en est disponible en ligne 5 . Les Collecta n'occupent qu'une infime partie de ce manuscrit de 314 folios : les distinctions proprement dites se trouvent aux folios 164r à 174r, et elles sont complétées par une table au fol. 174r-v.

Le manuscrit, dont on trouvera une description détaillée en annexe à cet article, contient essentiellement des textes destinés à des prédicateurs : sermons (par Nicolas de Dinkelsbühl ou Johannes Keck en particulier), mais aussi artes praedicandi de Jean de Galles ou Jacques de Saraponte. Même un traité médical, le De quatuor complexionibus d'un certain Magister Alexander Hispanus, dont on pourrait juger la présence de prime abord incongrue dans ce manuscrit, s'avère être un texte fortement moralisé dont un prédicateur aurait très bien pu tirer profit ${ }^{6}$. Il pourrait donc s'agir d'un manuscrit personnel d'un prédicateur, rassemblant en un volume de miscellanées l'essentiel des textes nécessaires à nourrir son activité.

Le manuscrit ne comporte pas de colophon, il n'est pas daté précisément, mais une note de possesseur sur le contre-plat supérieur indique qu'il a été donné le 21 juin 1505 par Johannes Mocz et Leonhardus Frinda au monastère alors bénédictin de Benediktbeuern (Bavière, à une soixantaine de kilomètres au sud-ouest de Munich), pour le salut d'Udalricus Zapp. Selon la même note, le don comprenait trois autres manuscrits : un Speculum Ecclesie d'Innocent III, un Compendium theologice veritatis, et un Tractatus super decem precepta de Nicolas de Dinkelsbühl. ${ }^{7}$ L'abondance de textes

\footnotetext{
4. Lacombe 1927.

5. urn:nbn:de:bvb:12-bsb00079191-5

6. Thorndike 1955 et 1958.

7. "Hic liber datus est nostro monasterio Benedictumpeuren cum tribus alys videlicet Speculum Ecclesie Innocentii Pape Tertii,
}

d'auteurs allemands (Nicolas de Dinkelsbühl, Johannes Keck, Johannes Schiltpacher et dans une moindre mesure Thomas Ebendorfer), ainsi que la présence de gloses en allemand dans une note reprenant les Summule logicales de Pierre d'Espagne au fol. 254 confirment une origine locale du manuscrit, probablement copié dans le sud de l'Allemagne.

Outre l'écriture, deux éléments nous permettent cependant de placer la composition du manuscrit dans la seconde moitié du XV $\mathrm{XV}^{\mathrm{e}}$ siècle. Le texte daté le plus récent de l'ensemble est une série de quarantedeux Sermones figuraliter distincti de sanctis per circulum anni, sélectionnés parmi les sermons de Johannes Keck (voir la description complète en annexe), et copiés aux folios 220r-252v. Ces sermons ont été mis par écrit par leur auteur lui-même en 14471449, à l'abbaye bénédictine de Tegernsee en Bavière, à une cinquantaine de kilomètres au sud de Munich, qu'il avait rejointe en 1442. Les manuscrits autographes en sont conservés aujourd'hui à Munich, Bayerische Staatsbibliothek, sous la cote $\mathrm{clm} 19606$ et clm 19607. ${ }^{8}$ La présence d'une sélection de ces sermons fournit donc le terminus post quem pour l'ensemble du manuscrit. Quant à la date de copie du texte qui nous intéresse plus particulièrement dans ces miscellanées, il est intéressant de noter qu'un autre texte fournit au cahier concerné un terminus post quem quasi identique. Les Collecta (fol. 167r-174v) occupent la première partie du quinzième cahier (fol. 167r-178v). Elles sont suivies d'un traité anonyme De antichristo (fol. 175r$180 \mathrm{v}$ ), à cheval sur ce cahier et le suivant (fol. 179r192v). Après un autre traité De septem gradibus contemplationis (fol. 181r-185r), ce seizième cahier est conclu par le Compendium humane salvationis de Johannes Schlitpacher (fol. 185v-192v). Or cette œuvre est datée par la mention dans son prologue du séjour de l'auteur au monastère de St. Ulrich $\delta$ Afra à Augsburg, où il a composé le texte. Le séjour de Johannes Schiltpacher est daté de 1441-1442, date après laquelle nous pouvons donc considérer

et Compendium theologice veritatis Hugonis, et Tractatus super decem precepta magistri Nicolai Dinckelspyl a dominis Johanne Mocz et Leonhardo Frinda pro salute domini Udalrici Zapp, anno Domini 1505 in profesto sancti Achacii et sociorum eius"

8. Sur la vie de Johannes Keck et la chronologie de ses œuvres, voir Rossmann 1983, spécialement col. 1101-1102 pour les sermons concernés.

9. Vollmann 2007. 
que les cahiers 15 et 16 ont été copiés - et donc les Collecta qui nous intéressent plus particulièrement ici.

Les Collecta nous sont donc transmises par un manuscrit copié dans le sud de l'Allemagne dans la seconde moitié du XV siècle. Mais qu'en est-il de leur texte?

Georges Lacombe a, le premier, porté attention à ces quelques folios, dans le cadre de ses recherches sur la vie et les œuvres de Prévostin de Crémone $^{10}$. Lacombe voulait voir dans les Collecta une version abrégée de la Summa super Psalterium de Prévostin de Crémone, un commentaire sur les Psaumes incomplet puisqu'il s'achève au Psaume 59. Il appuyait cette théorie sur une constatation assez simple : il a établi qu'environ environ un tiers des distinctions des Collecta (trente distinctions) ont un équivalent dans la Summa super Psalterium de Prévostin. Or nous connaissons de cette ouvre environ un tiers seulement de ce que serait un commentaire complet. Il n'en fallait pas plus pour se laisser tenter à voir dans les Collecta la preuve que Prévostin avait bien composé un commentaire complet des Psaumes, dont les deux tiers seraient aujourd'hui perdus. Les distinctions des Collecta ne trouvant pas d'équivalent dans ce que nous connaissons de la Summa super Psalterium seraient donc les témoins indirects d'une partie aujourd'hui disparue de ce commentaire. Lorsqu'il étudie les relations entre les Collecta, la Summa super Psalterium de Prévostin, la Summa Abel de Pierre le Chantre et les Distinctiones de Pierre de Poitiers, Lacombe va même jusqu'à avancer l'hypothèse que les Collecta, dérivées de Distinctiones Prepositini aujourd'hui perdues, pourraient être la source commune des trois autres ouvres ${ }^{11}$. Philip Moore, dans son étude des ouvres de Pierre de Poitiers, a accepté l'hypothèse de G. Lacombe faisant des Collecta le vestige d'une collection complète de Distinctiones perdues de Prévostin, et la source commune des trois œuvres mentionnées plus haut, apportant simplement quelques ajustements dans l'ordre proposé de leur rédaction ${ }^{12}$.

Mais Riccardo Quinto a brillamment démontré que la distinction sur «Timor» offerte par les

10. Lacombe 1927, en particulier le chapitre IV, p. 104-130.

11. Lacombe 1927, p. 126-130.

12. Moore 1936, p. 92-96.
Collecta, avec sa division en sept parties et l'usage de l'expression "timor reverentialis", emploie une structure et un vocabulaire incompatibles à la fois avec les propres enseignements de Prévostin de Crémone sur "Timor», et avec la pensée théologique du début du XIII ${ }^{\mathrm{e}}$ siècle. Il a également montré que la division septénaire de "Timor" et l'usage de l'expression "timor reverentialis" étaient typiques des XIV-XV siècles, prouvant ainsi que l'attribution des Collecta à Prévostin de Crémone devait être rejetée $\mathrm{e}^{13}$.

Nous pouvons ajouter à cela la présence apparemment anachronique d'un distique en appui de la distinction sur «Sensus sacre Scripture» :

Littera gesta docet, quid credas allegoria

Moralis quid agas, quid speras anagogia

La plus ancienne occurrence de ces vers a été identifiée par Henri de Lubac dans l'œuvre du Dominicain Augustin de Dacie, connu également sous le nom de Aage de Danemark († 1285), qui les a employés dans son Rotulus pugillaris, ca. $1260^{14}$. Cependant, Stephen Metzger a récemment relevé l'usage du même vers par Gérard d'Abbeville dans son Principium resumptum, composé également vers $1260^{15}$. Il se peut donc que le distique ait été en circulation assez commune au milieu du XIII ${ }^{e}$ siècle, sans qu'il paraisse pour autant vraisemblable d'en faire remonter l'usage jusqu'à la première décennie du siècle, lorsque Prévostin était encore actif. Qui plus est, le distique tel qu'on le trouve aussi bien chez Augustin de Dacie que chez Gérard d'Abbeville, se termine différemment: au lieu de quid speras anagogia comme dans les Collecta, ces deux auteurs donnent quo tendas anagogia. La variante des Collecta, quid speras, est absente des deux versions les plus anciennes connues, mais elle correspond en revanche au distique tel qu'il a été employé et popularisé par Nicolas de Lyre dans sa Postille, vers 1330, et dans son prologue à la Glose ordinaire. Cet indice pointe donc également vers une rédaction tardive des Collecta, après 1330 .

13. Quinto 1989.

14. De Lubac 1959, I, p. 23-24, et II, p. 425-439. Sur ce distique, voir également Châtillon 1964, et l'édition du Rotulus pugillaris dans Walz 1955. Autres références dans Walther 1963-69, nr. 13899.

15. Metzger 2017, p. 162, et Annexe 2, p. 457. 
Les Collecta ex distinctionibus Prepositini ne peuvent donc être considérées comme les héritières directes d'une ouvre perdue de Prévostin de Crémone. Elles semblent cependant bien emprunter à un fonds de distinctions de la fin du $\mathrm{XII}^{\mathrm{e}}$ et du début du XIII ${ }^{\mathrm{e}}$ siècle, bien antérieures donc à la composition des Collecta, tout en ajoutant d'autres distinctions plus contemporaines comme l'a montré Riccardo Quinto pour "Timor». Lacombe a établi un tableau notant les correspondances ou similitudes entre les distinctions des Collecta et quatre autres ouvres: la Summa super Psalterium de Prévostin, la Summa Abel de Pierre le Chante, les Distinctiones de Pierre de Poitiers, et une version schématisée des distinctions de Pierre de Poitiers que l'on trouve associée à la Summa super Psalterium de Prévostin dans le manuscrit Paris, BnF, Latin $454^{16}$. Moore s'est également attelé à comparer le contenu de ces œuvres. Tous deux constatent un phénomène surprenant: parmi les 1250 distinctions de la Summa Abel et les 225 de la Summa super Psalterium de Prévostin, trente sont partagées par les deux ouvres, et ce même groupe de trente distinctions est également partagé par les Collecta. Parmi les 1300 distinctiones de Pierre de Poitiers, cinq se trouvent également dans la Summa super Psalterium, tandis que sept se retrouvent à l'identique et dix-huit sont en partie identiques dans les Collecta. Dans le même temps, la Summa Abel et les Distinctiones de Pierre de Poitiers ont en commun 400 distinctions, soit près du tiers de leur contenu. Nous avons pu noter par ailleurs que la toute première distinction des Collecta, sur les quatre temps de l'année rapportés aux quatre temps du monde, pourrait bien être tirée du Tractatus de officiis de Prévostin. Dans le prologue, celui-ci développe en effet longuement cette comparaison, dans des termes proches de ceux de la distinction ${ }^{17}$.

Malheureusement, Lacombe et Moore n'ont pas suffisamment documenté leurs conclusions pour que nous puissions les vérifier précisément aujourd'hui. Moore, jugeant le tableau comparatif des ouvres qu'il avait réalisé trop long pour être publié, s'est contenté de nous livrer ses conclusions en une demi page. Lacombe, lui, nous a bien laissé un tableau comparatif pointant les correspondances des distinctions des Collecta avec, notamment, la Summa super Psalterium, les Distinctiones de Pierre de Poitiers et la Summa Abel. Pour juger de la nature de cette intertextualité affirmée entre les Collecta et d'autres collections de distinctiones, il m'est donc apparu nécessaire de comparer le texte des distinctions censées être identiques. J'ai utilisé pour cela le tableau de Lacombe, et choisi d'étudier la première des distinctions qu'il a données comme communes à l'ensemble des trois autres œuvres qu'il a considérées, c'est-à-dire la Summa super Psalterium, la Summa Abel, et deux versions (texte continu et texte schématique) des Distinctiones de Pierre de Poitiers. Cette distinction sur Dextera comporte 6 membres dans les Collecta:

Est dextera qua

- Deus pater operatur

- Christus homo exaltatur

- homo temporaliter prosperatur

- penitens reconciliatur

- justus delectatur

- sanctus glorificatur, scilicet

- filius Dei : Dextera Domini fecit virtutem <Ps. 117, 16>

- meritum Christi : In potentatibus salus dextere ejus $<$ Ps. 19, 7>

- prosperitas mundi : Non declinabis <Ex. 23, 6>

- et favor gratie : Dextera tua suscepit me <Ps. 62, 9>

- amor Dei : Nesciat sinistra tua <Mt. 6, 3>

- vita eterna : Delectationes in dextera tua $<$ Ps. 15, 10>

Si elles contiennent certains des membres, aucune des autres œuvres considérées par Lacombe ne présente en fait une distinction identique.

Dans la Summa super Psalterium, éditée ci-dessous, la distinction ne comporte que cinq membres. Le premier et le quatrième membre correspondent respectivement au premier et troisième membre des Collecta, le deuxième présente des similitudes (essentiellement la citation biblique) sans être identique, le troisième n'a pas d'équivalent dans les Collecta, et le cinquième présente une certaine similitude avec le sixième membre dans les Collecta.

16. Lacombe 1927, p. 122-124.

17. Prévostin de Crémone 1969, p. 3-6. 
A = Assisi, Sacro Convento, 55, f. 20r

$\mathrm{P}=$ Paris, BnF, Latin 454, f. 97rb

Quinque modis dicitur dextera.

Nam dicitur ${ }^{18}$ dextera qua Deus Pater operatur ${ }^{19}$, scilicet Filius Dei, de qua dicitur : Dextera Domini fecit virtutem, dextera Domini exaltavit me etc. ${ }^{20}\langle$ Ps. 117, 16>.

Est dextera in qua ${ }^{21}$ homo assumptus potentatur, scilicet divinitas Christi, unde dicitur : In potentatibus salus dextere ejus $<$ Ps. 19, 7>.

Est dextera qua ${ }^{22}$ homo spiritualis ${ }^{23}$ gloriatur, scilicet favor et propitiatio ${ }^{24}$ Dei, de qua hic ${ }^{25}$ dicitur : A resistentibus dextere tue etc. $<$ Ps. 16, $8>$ et ibi in titulo pro verbis ${ }^{26}$ Chusi $^{27}$ filii Gemini. $<$ Ps. 7>

Est dextera qua $^{28}$ homo mundialis delectatur, scilicet prosperitas mundialis, unde dicitur : Non declines ad dexteram ${ }^{29}$ neque ad sinistram <cf. Dt. 2, 27 vel 5, 32, vel Jos. 23, 6, vel 1 Reg. 6, 12, vel 2 Reg. 2, 19, vel 2 Par. 34, 2, vel Is. 30, 21 > scilicet ad dexteram mundialis prosperitatis et sinistram ${ }^{30}$ mundialis adversitatis.

Est dextera ad quam homo sanctus colletatur ${ }^{31}$, scilicet vita eterna, unde dicitur : Leva ejus sub capite meo et dextera illius amplexabitur me $<$ Ct. 2, 6 vel 8, 3>; per levam intelligimus temporalia, per dexteram intelligimus eterna.

Dans la Summa Abel comme dans les deux versions des Distinctiones de Pierre de Poitiers, la distinction sur Dextera est très proche, mais diverge toujours de la version des Collecta. Dans ces œuvres elle ne comporte que quatre membres. Là encore le premier membre est identique à celui des Collecta, mais les trois autres membres n'ont pas d'équivalent.

Summa Abel, d'après le manuscrit Reims, Bibliothèque Municipale, 508 (F. 481), f. 26v-27r :

18. nam dicitur] est $P$

19. qua deus pater operatur] in qua pater miracula operatur $P$

20. etc] om. $P$

21. in qua] om. $A$

22. qua] de qua $P$

23. spiritualis] spiritualiter $P$

24. propitiatio] propinatio $P$

25. hic] om. $P$

26. pro verbis] om. $P$

27. Chusi] Cusi $A$

28. qua] que $A$

29. ad dexteram] a dextera $A$

30. scilicet ad dexteram mundialis prosperitatis et sinistram] om. per hom. $P$

31. colletatur] collocatur $P$
Dextera Dei dicitur :

Filius Dei, unde : Dextera Domini fecit virtutem, id est Christus.

Equalitas cum Patre, unde : Sede a dexteris meis, id est conregna equalis mihi.

Protectio divina, unde: Providebam Dominum in conspectu meo semper quoniam a dexteris est mihi ne commovear, ut per dexteram accipiatur equalitas quam habet Christus cum Patre. Item : Fiat manus tua super virum dextere tue etc.

Retributio eterna, unde : collocabuntur hii quidam a dextris Per dexteram intelligitur eternitas, per levam hec temporalia vel misterium incarnationis Christi.

Distinctiones de Pierre de Poitiers :

\begin{tabular}{|c|c|}
\hline $\begin{array}{l}\text { Texte schématique d'après } \\
\text { le manuscrit Paris, BnF, } \\
\text { Latin 454, f. 8r }\end{array}$ & $\begin{array}{l}\text { Texte continu, d'après } \\
\text { le manuscrit Paris, } \\
\text { Mazarine, } 777, \text { f. } 8 \mathrm{v}\end{array}$ \\
\hline $\begin{array}{l}\text { Dextera Domini dicitur: } \\
\text { - Filius Dei, ut dextera Domini } \\
\text { fecit virtutem. } \\
\text { - Equalitas cum Patre, ut : } \\
\text { Sede a dexteris meis. } \\
\text { - Protectio divina, ut : A dexte- } \\
\text { ris est mihi ne commovear <Ps. } \\
\text { 15, 8>, item : Fiat manus tua } \\
\text { super virum dextere tue. } \\
\text { - Retributio eterna, ut collo- } \\
\text { cabuntur boni ad dexte- } \\
\text { ram, mali ad sinistram. }\end{array}$ & $\begin{array}{l}\text { Dextera Domini dicitur } \\
\text { Filius Dei, ut: Dextera Domini } \\
\text { fecit virtutem. Equalitas cum } \\
\text { Patre, ut: Sede a dexteris meis. } \\
\text { Et protectio divina, ut: Fiat } \\
\text { manus tua super virum dextere. } \\
\text { Et retributio eterna, ut: } \\
\text { collocabuntur hii quidam } \\
\text { a dexteris ejus, hii autem a } \\
\text { sinistra. }\end{array}$ \\
\hline
\end{tabular}

Par ailleurs, mes sondages semblent indiquer que les Collecta, lorsqu'elles ne se rapprochent pas de Prévostin, Pierre de Poitiers ou Pierre le Chantre, ne puisent pas non plus leur matière dans les collections de distinctions les plus répandues au $\mathrm{XIII}^{\mathrm{e}}$ et $\mathrm{XIV}^{\mathrm{e}}$ siècles : les Distinctiones de Nicolas de Gorran, Maurice de Provins ou Nicolas de Biard, ou la Summa de abstinentia de ce dernier.

On peut donc avancer l'hypothèse que les Collecta, si elles ne peuvent être considérées comme le témoin tardif mais fidèle d'une ouvre du tournant des XII ${ }^{e}$ et XIII ${ }^{e}$ siècles, sont en revanche une libre adaptation d'un matériau bien antérieur à la copie du manuscrit. Elles sont marquées par l'irruption de notions théologiques propres à la fin du Moyen Âge, à partir de la fin du XIV siècle, comme l'a montré Riccardo Quinto pour "Timor». Cette courte collection est donc le témoin d'une permanence à travers les siècles des schémas de pensée véhiculés par les distinctions, en même temps que de la grande liberté avec laquelle celles-ci pouvaient être transmises, adaptées, et ainsi sans cesse revivifiées. 
Annus: quattuor temporibus anni comparantur quattuor tempora mundi, id est ornato virtutibus.

Comparatur $\left\{\begin{array}{l}\text { hycmi } \\ \text { veri } \\ \text { cstati } \\ \text { autumpno }\end{array}\right\}$ tcmpus $\left\{\begin{array}{l}\text { peccati ct miscric } \\ \text { eruditionis et doctrine } \\ \text { plenitudinis ct gratic } \\ \text { collectionis et sufficientie }\end{array}\right\}$ quod $\left\{\begin{array}{l}\text { duravit ad datam lcgem } \\ \text { duravit ad Christum } \\ \text { modo instat } \\ \text { erit in patria celesti }\end{array}\right.$

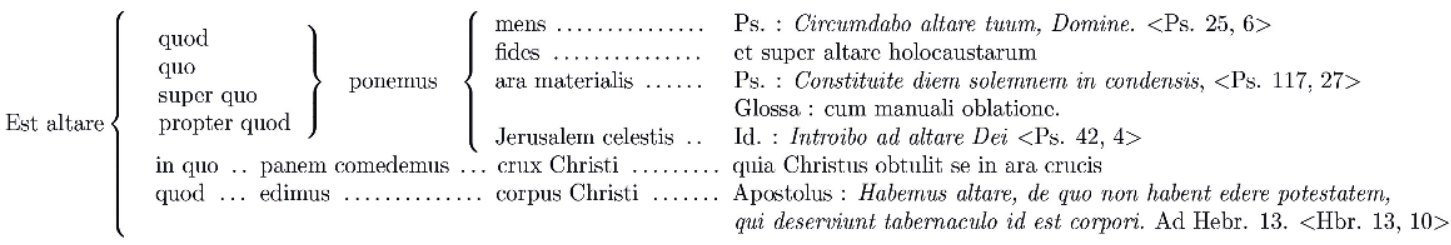

Item sancti apostoli dicuntur montes propter quasdam laudabiles proprietates montium.

Ascendit Christus in $\left\{\begin{array}{l}\text { desertum } \\ \text { montcm } \\ \text { montem } \\ \text { montem } \\ \text { asinam } \\ \text { crucem } \\ \text { celum }\end{array}\right\}$ ut $\left\{\begin{array}{l}\text { jejunaret } \\ \text { informarct discipulos } \\ \text { se transfiguraretur } \\ \text { solus araret } \\ \text { se humiliaret } \\ \text { triumpharet } \\ \text { semper regnaret }\end{array}\right\}$ in $\left\{\begin{array}{l}\text { exemplum } \\ \text { documcntum } \\ \text { solacium } \\ \text { remedium } \\ \text { refugium } \\ \text { precium } \\ \text { premium }\end{array}\right.$

Deus $\left\{\begin{array}{l}\text { quosdam audit } \\ \text { quosdam non audit }\end{array}\right\}$ ut $\left\{\begin{array}{l}\text { puniat, Ps. : Audivit Dominus et distulit et ignis. } .<\text { Ps. } 77,21> \\ \text { solacium ferat, id. : Clamavi et exaudivit me }<\text { Ps. } 3,5> \\ \text { saluet : unde dictum est Paulo : Sufficit tibi gratia mea }<2 \text { Cor. } 12,9> \\ \text { dampnet : Scimus autem quia Deus peccatores non audit. }<\text { Io. } 9,31>\end{array}\right.$

Arboris bone $\left\{\begin{array}{l}\text { radix habundat humore } \\ \text { et folia plena sunt uirore } \\ \text { et flos habundat odore } \\ \text { et fructus plenus est sapore }\end{array}\right\}$ id est $\left\{\begin{array}{l}\text { affectio deuotione } \\ \text { verba edificatione } \\ \text { conuersatio oppinione } \\ \text { operatio dilectione }\end{array}\right.$

Bonorum Domini : $\left\{\begin{array}{l}\text { incipientes servi ........ deflent peccata } \\ \text { perficientes mercenarii ... implent mandata } \\ \text { perficientes filii.......... ardent consilia }\end{array}\right\}$ offerunt $\left\{\begin{array}{l}\text { turturem columbam ...penitentiam } \\ \text { hedum...............abstinentiam } \\ \text { agnum.............. patientiam }\end{array}\right\}$

Confessio quam $\left\{\begin{array}{l}\text { extorquet : involvens confusio } \\ \text { deducit : timoris actio } \\ \text { facit : doloris afflictio } \\ \text { producit : vera cordis contritio }\end{array}\right\}$ ut $\left\{\begin{array}{l}\text { vide proditorum } \\ \text { demonum } \\ \text { divitis cpulationis } \\ \text { penitentis }\end{array}\right.$

1,2 Mt. 27 : Peccavi, tradens sanguinem justum. <Mt. 27, 4> Evangelia : Jesu fili Dei, cur venisti etc. $<$ Cf. Mt. 8,$29 ;$ Mc. 5,$7 ;$ Lc. $8,28>$

3,4 Luc. 16 : Pater Abraham, miserere mei. <Lc. $16,24>$ Luc. $15:$ Pater, peccavi in celum et coram te. $<$ Lc. 15,18 vel $21>$

Est casus $\left\{\begin{array}{l}\text { devote vencrationis } \\ \text { humane fragilitatis } \\ \text { voluntarie precipitationis } \\ \text { eterne dampnacionis }\end{array}\right\}$ quo $\left\{\begin{array}{l}\text { ceciderunt } 24 \text { seniores ante tronum }<\text { Apc. } 5,8> \\ \text { cadit septies in die justus }<\text { Pr. } 24,16> \\ \text { cecidit Hely et mortuus est }<1 \mathrm{Rg} 4: 18> \\ \text { cadet Antichristus cum dominatus fuerit pauperum }<\text { Ps. } 9,31>\end{array}\right.$

$[167 \mathrm{v}]$ Reverentie signum $\left\{\begin{array}{l}\text { veniale peccatum } \\ \text { mortale peccatum } \\ \text { extreme judicium }\end{array}\right.$

Est calix $\left\{\begin{array}{l}\text { in quo mors bibit ................. affluentia temporalium } \\ \text { in quo sitis sccleris extinguitur...... ipse Deus }\end{array}\right.$

quo mundus redimitur............. sanguis Christi

1 Accipe aureum calicem et propina omnibus gentibus < Jr 25:17>

2 Ps. : Dominus pars hereditatis mee et calicis mei $\langle$ Ps. 15,5$\rangle$

3 Id. : Calix meus inebrians, quam preclarus est $\langle$ Ps. 22, 5$\rangle$ 
Item 4 or surt proprietates in cane cuilibet prelato competentes, scilicet $\left\{\begin{array}{l}\text { latratus ........... a malo terreat } \\ \text { lingua medicinalis ..... sanitatem conferat } \\ \text { odoratus ............ spem patric celestis obtincat } \\ \text { fidelitas ............. si opus est proximo se morti subiciat }\end{array}\right.$

Est circumcisio $\left\{\begin{array}{l}\text { carnis, Indeorum institutio } \\ \text { oris, vocorum moderatio } \\ \text { cordis, viciorum remocio }\end{array}\right\}$ et ista est $\left\{\begin{array}{l}\text { munc pro[hi]bita } \\ \text { consulta } \\ \text { precepta }\end{array}\right.$
1 Si circumcidimini nee Christus nobis prodest $<$ Gal. $5,2>$
2 Incircumcisus labiis ego sum $<$ Ex. $6,30>$
3 Circumcidimini, et removete prepucia cordium vestrorum $<\mathrm{Jr} .4,4>$

Est calciarnentum $\left\{\begin{array}{l}\text { municns, Evangclium } \\ \text { celans, humilitas Christi } \\ \text { vivificans, Passio }\end{array}\right\}$ Christi $\left\{\begin{array}{l}\text { Preparati pedes in Evangelium pacis }<\text { Eph. } 6,15> \\ \text { Non sum dignus solvere corrigiam calciamentorum }<\text { Mc. } 1,7 \text { vel Lc. } 3,16> \\ \text { In Idumeam extendam calciamentum }<\text { Ps. } 59,10 \text { vel } 107,10>\end{array}\right.$

Calciamentum munit contra $\left\{\begin{array}{l}\text { aspera } \\ \text { spinosa } \\ \text { venenosa }\end{array}\right\}$ sic Evangelium contra $\left\{\begin{array}{l}\text { superbiam : Jugum enim meum suave est }<\mathrm{Mt} .11,30\rangle \\ \text { avariciam : Nollite solliciti esse }\langle\text { Lc. } 12,11 \text { vel } 22\rangle \\ \text { luxuriam : Dedi vobis potestatem calcandi }<\text { Lc. 10, 19> }\end{array}\right.$

Clamoris occasio $\left\{\begin{array}{l}\text { ignis caro ........ Mic. } 6: \text { Ignis in domo impii }<\text { Mch. } 6,10\rangle \\ \text { aqua mundus .... Mt. } 8: \text { Domine, salva nos, perimus }<\mathrm{Mt} .8,25\rangle \\ \text { hostis dyabolus ... Ps. : Eripe me de inimicis meis, Deus meu. }<\text { Ps. } 58,2>\end{array}\right.$

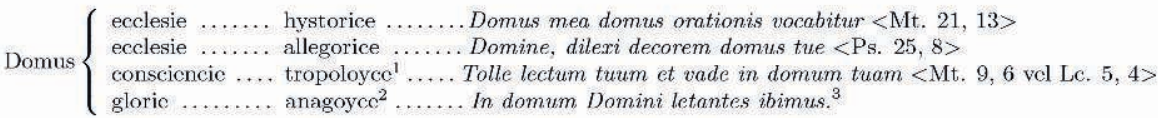

Est digitus quo $\left\{\begin{array}{l}\text { ommia creantur } \\ \text { omnia gubernantur } \\ \text { et fideles anime illustrantur }\end{array}\right\}$ scilicet $\left\{\begin{array}{l}\text { trimus Deus ............ Ysa., Quis appendil }<\text { Is. } 40,12> \\ \text { Spiritus sanctus ........ Si in digito Dei }<\text { Lc. 11, 20 }> \\ \text { Spiritus sancti domm .... Qui docet manus meas }<\text { Ps. 17, 35 vel 143, 1 }>\end{array}\right.$

${ }^{1}$ tropoloyce] sic pro tropologice

2 anagoyce) sic pro anagogice
${ }^{3}$ Anticnnc. Renć-Jcan Hesbert, Corpus antiphonalium Officii, nr, 3229 (Cf. Ps. 121, 1: Loctatus sum in his qua dicta sunt miki : In domum Domini ibimus).

Diligere ex $\left\{\begin{array}{l}\text { corde } \\ \text { anima } \\ \text { virtutc }\end{array}\right\}$ est diligere ex $\left\{\begin{array}{l}\text { deliberationis consilio } \\ \text { affectionis desiderio } \\ \text { virtutis cxcrcicio }\end{array}\right.$

Gradus dilectionis $\left\{\begin{array}{l}\text { insupcrabilis } \\ \text { inseparabilis } \\ \text { singularis } \\ \text { insaciabilis }\end{array}\right\}$ in quo $\left\{\begin{array}{l}\text { dilectio Dei a temporalium dilectione non supcratur } \\ \text { Deus a. memoria non separatur } \\ \text { solus Deus pre omnibus diligitur } \\ \text { fidelis totus in amorem Dei resolvitur }\end{array}\right.$

[168r] Diligitur Deus in gradu $\left\{\begin{array}{l}\text { primo ex corde et anima et virtute, sed non ex tota virtute } \\ 2^{\circ} \text { ex toto corde sed non ex } x^{5} \text { tota anima } \\ 3^{\circ} \text { ex toto corde ct tota anima sed non cx tota virtute } \\ 4^{\circ} \text { ex toto corde et tota anima et tota virtute }\end{array}\right.$

Anima in gradu $\left\{\begin{array}{l}1 \text { desponsatur ...... Sponsabo te in misericordia et miserationibus }\langle\text { Os. } 2,19\rangle \\ 2 \text { traducitur ....... Ecce vir tuus et post me ingredi non cessabis }<\text {.Jr. } 3,14,19\rangle \\ 3 \text { copulatur ......... Qui adheret Deo unu.s spiritus efficitur cum eo }\langle 1 \text { Cor, } 6,19\rangle \\ 4 \text { fecundatur ....... Fitioli mei, quos iterum parturio donec formetur Christus in vobis }\langle\text { Gal. } 4,19\rangle^{6}\end{array}\right.$

Ordo diligendi $\left\{\begin{array}{l}\text { primo Deum super omnia } \\ 2^{\circ} \text { animam propriam } \\ 3^{\circ} \text { animam proximi plusquam corpus nostrum } \\ 4^{\circ} \text { corpus nostrum plusquam temporalia }\end{array}\right.$

$4^{\circ}$ corpus nostrum plusquam temporalia
$5^{\circ}$ corpus proximi plusquam nostra temporalia

Est deceptio $\left\{\begin{array}{l}\text { ulcionis } \\ \text { probacionis } \\ \text { utilitatis } \\ \text { dolositatis }\end{array}\right\}$ qua $\left\{\begin{array}{l}\text { Christus hamo divinitatis, mente, carne vicit dyabolum } \\ \text { Christus finxit se longitus ire probans discipulos in hospitalitate }{ }^{7}<\text { Lc. } 24,28> \\ \text { leu fingans se sacrificare Baali interfecit omnes sacerdotes }<\text { cf. } 4 \text { Rg. } 10\rangle \\ \text { dyabolus in specie serpentis decepit Evam }\end{array}\right.$

${ }^{4}$ ex tota virtute] post corr. in mary. ex ex toto corde

"sed non ex] add. in maro.

${ }^{6}$ Distinction similaire chez Richard de Saint-Victor, De IV gradibus violente carilatis, §26. Voir : Ives. Epâtre à Séverin sur la charilé. Richard de Saint-Victor. Les qualre degrés de la violente charité. Texte critique avec introduction, traduction et notes par Gervais Dumeige, Paris, J. Vrin, 1955, p. 89-181; spéxialement p. 153 et suivantes pour ce passago.

${ }^{7}$ in hospitalitate] add. in marg. 
Quidam discunt ut $\left\{\begin{array}{l}\text { vendant } \\ \text { sciant } \\ \text { appareant } \\ \text { proficiant } \\ \text { instruant }\end{array}\right\}$ et est $\left\{\begin{array}{l}\text { symoniaca pravitas } \\ \text { humana curiositas } \\ \text { ambiens vanitas } \\ \text { prudens simplicitas } \\ \text { et fraterna caritas }\end{array}\right.$

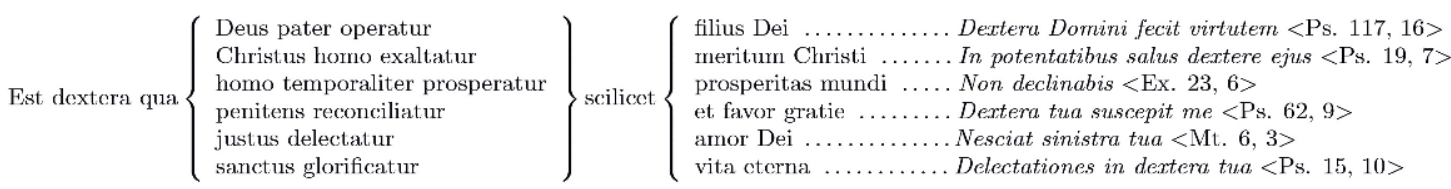

Elementum ex $\left\{\begin{array}{l}\text { igne } \\ \text { aere } \\ \text { aqua } \\ \text { terra }\end{array}\right\}$ in $\left\{\begin{array}{l}\text { oculis } \\ \text { lingua } \\ \text { lumbis } \\ \text { manibus }\end{array}\right\}$ est $\left\{\begin{array}{l}\text { curiositas } \\ \text { loquacitas } \\ \text { voluptas } \\ \text { crudelitas }\end{array}\right.$

Quo contra Christus ante oculos velamine sustimuit, coram tondente sicut ovis obmutuit,

lancea latus ejus miles apperuit, manus et pede crucifixos habuit.

$[168 \mathrm{v}]$ Etas $\left\{\begin{array}{l}\text { prima ab Adam } \\ \text { 2a a Noe } \\ \text { 3a ab Abraham } \\ \text { 4a a David } \\ \text { 5a a transmigratione Babylonis } \\ \text { 6a a Christo } \\ \text { 7a a Passione Christi } \\ \text { 8a a die judicii }\end{array}\right\}$ usque ad $\left\{\begin{array}{l}\text { Noe } \\ \text { Abraham } \\ \text { David } \\ \text { transmigrationem Babylonis militantium hominum } \\ \text { Christum } \\ \text { finem seculi } \\ \text { diem judicii } \\ \text { eternum quiescentium animarum refrigeriurn corporum }\end{array}\right.$

Aliquando dicitur esse Domini $\left\{\begin{array}{l}\text { eterna gubernacione vel processione } \\ \text { creatione } \\ \text { voluntaria vel invita subjectione } \\ \text { recreatione }\end{array}\right\}$ ut $\left\{\begin{array}{l}\text { Filius vel Spiritus sanctus } \\ \text { mundus cum contentis } \\ \text { angelus et homo etiam malus } \\ \text { Ecclesia sanctorum }\end{array}\right.$

In esca carnali notatur $\left\{\begin{array}{l}\text { nitor } \\ \text { odor } \\ \text { sapor }\end{array}\right\}$ ut $\left\{\begin{array}{l}\text { resplendcat visui } \\ \text { redoleat olfactui } \\ \text { sapiat gustui }\end{array}\right.$

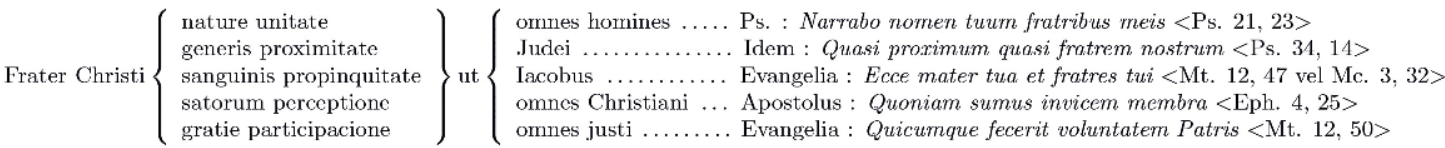

Est facies $\left\{\begin{array}{l}\text { ymaginis } \\ \text { indignationis } \\ \text { corporalis apparitionis } \\ \text { eterne retributionis }\end{array}\right\}$ scilicet $\left\{\begin{array}{l}\text { Filius Dei nondum incarnatus. Ps. : Ostende nobis faciem tuam, et salutare }<\text { Ps. } 84,8> \\ \text { ira Dei. Ps. : A facie ire indignationis tue }<\text { Ps. } 101,11> \\ \text { Filius Dei incarnatus. Ysa. : Faciem meam non averti }<\text { Is. } 50,6> \\ \text { visio Dei. Apostolus : Nunc videmus per speculum in enigmate }<1 \text { Cor. } 13,12>\end{array}\right.$

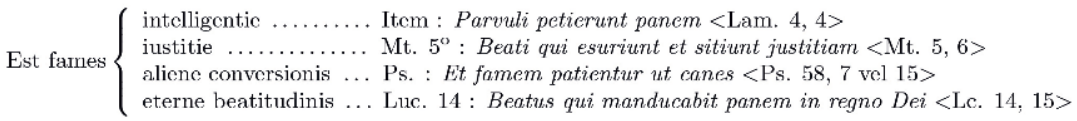

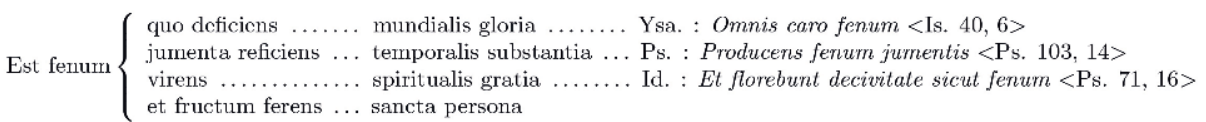

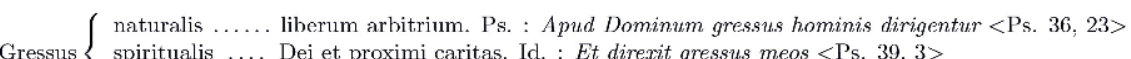

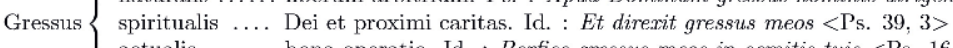

actualis ...... bona operatio. Id. : Perfice gressus meos in semitis tuis $\langle$ Ps. 16,5$\rangle$

Est gravitas $\left\{\begin{array}{l}\text { morum } \\ \text { corporum } \\ \text { viciorum }\end{array}\right\}$ que est $\left\{\begin{array}{l}\text { gratie } \\ \text { pene } \\ \text { culpe }\end{array}\right\}$ et hec est $\left\{\begin{array}{l}\text { laudabilis } \\ \text { compassibilis. Corpus quod corrumpitur aggravat animam }<\text { Sap. 9, 15 }> \\ \text { detestabilis. Et fili hominum scitote }<\text { Sir. 2, 11 }>^{9}\end{array}\right.$

${ }^{8}$ olfactui] sic in $m s ;$ on attendrait olfacto

${ }^{9}$ Citation scripturairc très abrégće, on lit dans la Vulgate: Respicite, filii, nationes hominum, et scitote quia nullus speravit in Domino et confusus est. 


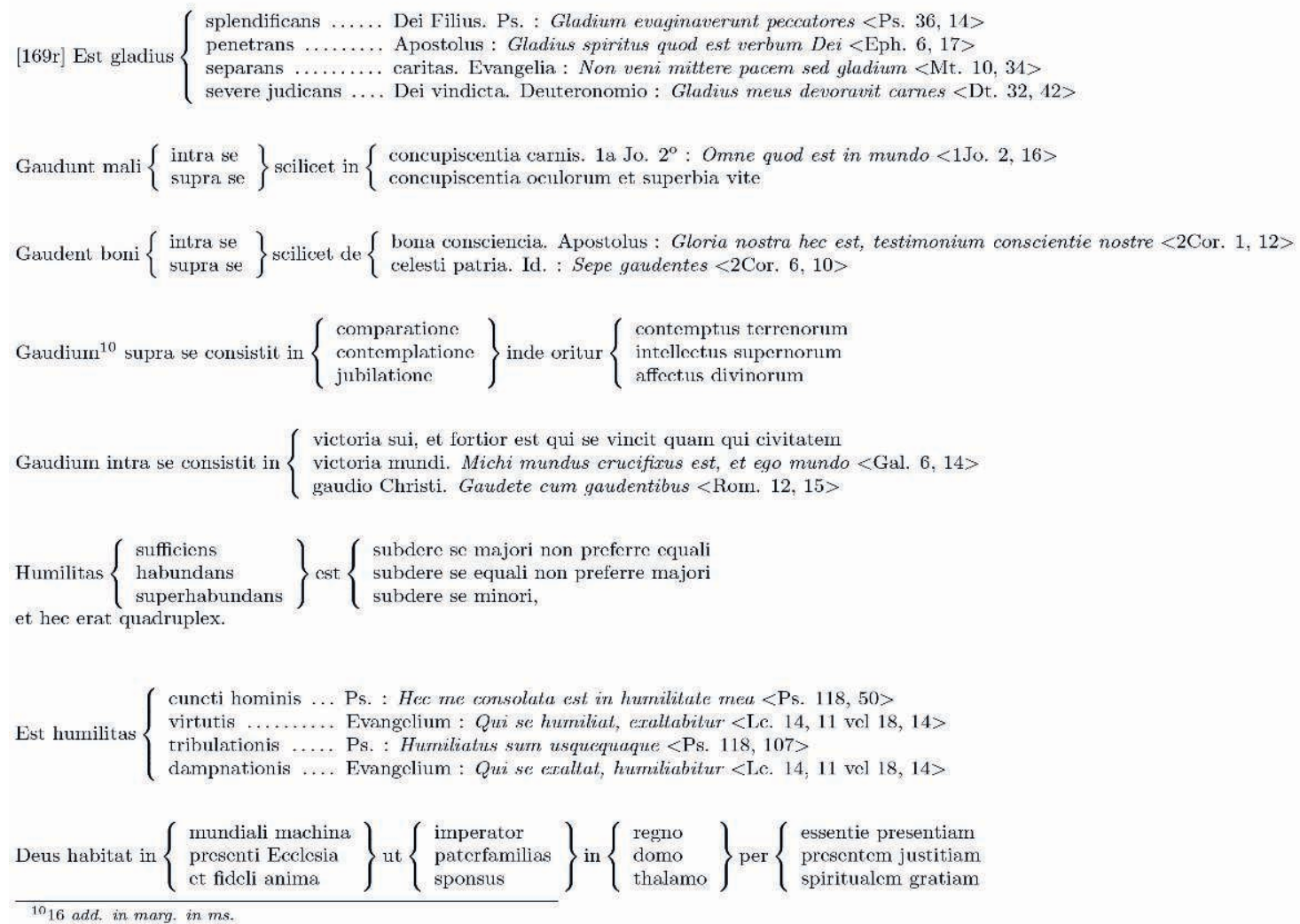

Est hereditas $\left\{\begin{array}{l}\text { quam }\left\{\begin{array}{l}\text { mali appetunt : temporalium congregatio } \\ \text { boni constituunt : fidelium collectio }\end{array}\right. \\ \text { quedam }\left\{\begin{array}{l}\text { justis in anime et corporis dissolutione : perfruitio eternitatis } \\ \text { beatis in anime et corporis conjunctione : gloria immortalitatis }\end{array}\right.\end{array}\right.$

1 Evangelium : Venite occidamus eum et nostra erit hereditas $\langle$ Mc. 12, 7>

2 Ps. : Postula a me et dabo tibi gentes hereditatem tuam $\langle$ Ps. 2,8$\rangle$

3 Id. : Dominus pars hereditatis mee $\langle$ Ps. 15,5$\rangle$

4 Id. : Tu es qui restitues $<$ Ps. $15,5>$

Quidam habitus $\left\{\begin{array}{l}\text { mutat et non mutatur } \\ \text { mutatur et non mutat } \\ \text { mutat ct mutatur } \\ \text { nec mutat nec mutatur }\end{array}\right\}$ ut $\left\{\begin{array}{l}\text { sapientia } \\ \text { cibus } \\ \text { anulus } \\ \text { camisia }\end{array}\right.$

Hereticus ut vulpes $\left\{\begin{array}{l}\text { est animal callidum } \ldots \ldots \ldots \text {. Ps. : Insidiatur quasi leo in spelunca sua }<\text { Ps. } 9,30> \\ \text { tortuosas querit vias } \ldots \ldots \ldots \text { Apostolus : Circueunt domos mulierum }<\text { cf. } 2 \text { Tim. } 3,6> \\ \text { et fetidum habet anhelitum ... Ps. : Sepulchrum patens est guttur eorum }<\text { Ps. } 5,11 \text { vel } 13,3>\end{array}\right.$

$[169 \mathrm{v}] \operatorname{Igniis}\left\{\begin{array}{l}\text { consummit ligna } \\ \text { purgat metalla } \\ \text { illuminat circumstantia } \\ \text { ct fructificat mirram que est arbor aromata ct igne cxusta magis purgatur }\end{array}\right.$

Est ignis $\left\{\begin{array}{l}\text { vetustatis : fomes peccati. Ps. : Vox Domini intercidentis flammam ignis }<\text { Ps. } 28,7> \\ \text { cupiditatis : appctitus vicii. Id. : Ignis et sulphur, et spiritus procellarum }<\text { Ps. } 10,7> \\ \text { perpetuitatis : pena inferni. Mt. } 25^{\circ}: \text { Discedite a me maledicti }{ }^{11} \text { in igne eternum }<\text { Mt. } 25,41> \\ \text { examinationis : probatio. Ps. : Igne me examinasti }<\text { Ps. } 16,3> \\ \text { purgationis : pena purgatorii. Id. : Transivimus per ignem et aquam }<\text { Ps. } 65,12> \\ \text { consumptionis : Deus. Deuteronomio : Deus noster ignis consumens }<\text { Dt. } 4,24> \\ \text { illuminationis : caritas. Evangelium, Luc. } 13^{12}: \text { Ignem veni mittere in terram }<\text { Lc. } 12,49>\end{array}\right.$

${ }^{11}$ maledicti] malign. sic in m.s.
${ }^{12}$ Luc. 13] add. interl. et in marg. 
Est ira $\left\{\begin{array}{l}\text { oculum inficiens } \ldots \ldots . \text { primus motus ire } \\ \text { oculum cecans ....... cum ira vertitur in odium } \\ \text { oculum purgans } \ldots . . . \text { cum quis irascitur peccatis suis } \\ \text { oculum illuminans } \ldots . \text { cum quis irascitur peccatis aliorum }\end{array}\right.$

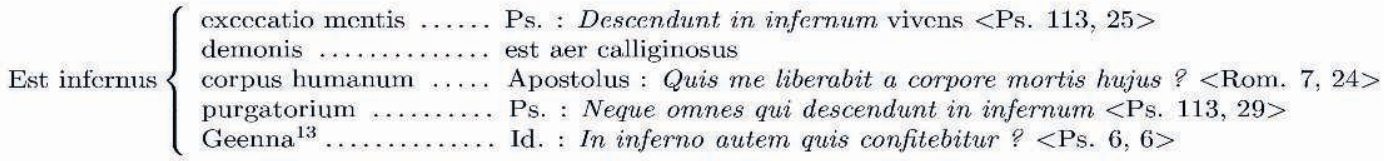

$\left\{\begin{array}{l}\text { malorum } \ldots . . . . \text { diligentes diligere, odientes odio habcre } \\ \text { infirmorum } \ldots . . . \text { rancorem animi dimittere sed satisfactionem }{ }^{14} \text { exigere }\end{array}\right.$

Est justitia $\left\{\begin{array}{l}\text { perfectorum } . . . . . \\ \text { utrumque dimittere scilicet iram et satisfactionem }\end{array}\right.$

meritorum ....... meritorum exigentia bonorum vel malorum

effectus ......... causa omni bonorum ipse Deus

1 Apostolus : Volentes justitiam suam constituere justitie Dei non sunt subjecti<Rom. $10,13>$

2 Secundum legem oculum pro oculo, dentem pro dente $<$ Ex 21, 24 vel Lv 24, 20 vel Dt 19, 21>etc.

3 Ps. : Judica, Domine, secundum justitiam meam $\langle$ Ps. 7,9$\rangle$

4 Justum est qui in sordibus est, sordescat adhuc $<$ Apc. $22,11>$

5 Ps. : Justitiam de celo prospexit $<$ Ps. 84, 12>

Derversitatis. Ps. : Dixit insipiens in corde suo 'non est Deus' $\langle$ Ps. 13,1$\rangle$ simplicitatis. Apostolus : Stulta hujus mundi elegit Deus ut fortia quasi confundat $\langle 1$ Cor. 1, 27 $\rangle$ humilitatis. Id. : Nichil predicavi vobis nisi Ihesum Christum et hunc crucifixum Judeis, quid scandalum gentibus autem stultitiam <cf. 1Cor. 2, 2>

Ignorantia eorum qui $\left\{\begin{array}{l}\text { scire potuerunt et noluerunt } \\ \text { scirc volucrunt ct non potucrunt } \\ \text { nec proponunt scire nec nescire }\end{array}\right\}$ peccatum $\left\{\begin{array}{l}\text { non excusat } \\ \text { excusat } \\ \text { attenuat }\end{array}\right.$

${ }^{13}$ Geenna] sic pro Gehenna
${ }^{11}$ satisfactionem] catisfactionem sic in $\mathrm{ms}$

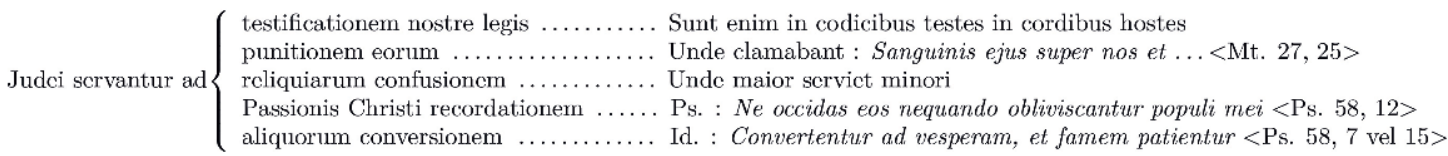

( nature et mentis ........ jus naturale. Video aliam legem in membris meis ${ }^{15}<$ Rom. $7,23>$

$[170 \mathrm{r}]$ Lex $\left\{\begin{array}{l}\text { menbrorum ct carnis .... fomes peccati. Repugnantem }{ }^{16} \text { legi mentis mee }<\text { Rom. } 7,23> \\ \text { peccati et mortis ........ ipsum peccatum. Et captivantem me in lege peccati et membris }<\text { Rom. } 7,23>\end{array}\right.$

factorum ct litcre ........ lex vetus. Apostolus : Lex neminem ducit ad perfectum $<$ Hbr. $7,19>$

spiritus et vite $\ldots \ldots \ldots \ldots$ Evangelium. Ps. : Benedictiones dabit legislator $\langle$ Ps. $83,8>$

In lege evangelica sunt $\left\{\begin{array}{l}\left\{\begin{array}{l}\text { precepta } \\ \text { consilia } \\ \text { promissa } \\ \text { sacramenta }\end{array}\right\} \text { in quibus meritum } \\ \text { inibus }\left\{\begin{array}{l}\text { premium } \\ \text { auxilium }\end{array}\right.\end{array}\right.$

Littera fit obscura ex $\left\{\begin{array}{l}\text { sententie difficultate. In principio erat verbum etc. }<\mathrm{Gn} .1,1> \\ \text { legentis infirmitate. Incrassatum est cor populi hujus }<\mathrm{Mt} .13: 15 \text { vel Act. } 28: 27> \\ \text { translationc figurc. Tenebrosa aqua in nubibus acris }<\mathrm{Ps} .17,12>\end{array}\right.$

translationc figurc. Tenebrosa aqua in nubibus acris $<$ Ps. $17,12>$
defectum scripture. Delictum oris eorum $<$ Ps. $58,13>$ etcetera.

Lilium habet in se $\left\{\begin{array}{l}\text { candorem } \ldots \ldots \ldots \ldots \ldots \ldots \text { hinc servetur candor conscientie : Lavabis me, et super nivem }<\text { Ps. } 50,9> \\ \text { odorem } \ldots \ldots \ldots \ldots \ldots \ldots \text { hinc servetur odor fame sicut luccat lux vestra }<\text { Mt. } 5,16>\end{array}\right.$

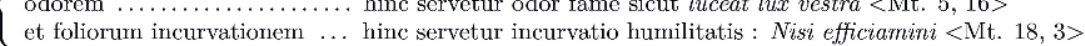

Loquitur Deus per $\left\{\begin{array}{l}\text { nature rationem. Ro. } 1 \text { : Invisibilia enim Dei per ea }<\text { Rom. } 1,20\rangle \\ \text { Scripture inspectionem. Ps. : Beatus qui in lege Dei meditatur }<\text { Ps. } 1,1-2>17 \\ \text { ministri explanationem. Id. : Erudimini, qui judicatis terram }<\text { Ps. } 2,10> \\ \text { occultam inspirationem. Id. : Audiam quid loquatur in me, Dominus Deus. }<\text { Ps. } 84,9>\end{array}\right.$

${ }^{15}$ in membris meis] corr. ex.repungnantem in membris

${ }^{16}$ repugnantem] repungnantern sic in $\mathrm{ms}$.

${ }^{17} \mathrm{Il}$ s'agit ćgalement d'une anticnnc. René-Jean Hesbert, Corpus antiphonalium Officii, nr. 1674 


\footnotetext{
$\int$ amarum : mundus. Ps. : Super maria fundavit eam ${ }^{18}<$ Ps. $23,2>$

Mare $\left\{\begin{array}{l}\text { dulcoratum : cor fidele. Exo. } 15 \text { invenit Moyses lignum }<\text { cf. Ex. } 15,25>\end{array}\right.$

( rubrum : baptismus. Tbidem : Pharao ${ }^{19}$ et equites ejus submersi sunt in Mare Rubro $<$ Ex. 15,4$\rangle$
}

Est mendacium $\left\{\begin{array}{l}\text { oris : hereticorum dogmata. Ps. : De execratione et mendacio }<\text { Ps. } 58,13> \\ \text { operis : operatio perversa. Si Christum verbis confiteris et factis abnegas, mendax es }<\text { cf. Tit. } 1,16> \\ \text { mutabilitatis : mutabilitas nostra. Ps. : Omnis homo mendax }<\text { Ps. } 115,2>\end{array}\right.$

Item mendacium oris triplex est, scilicet $\left\{\begin{array}{l}\text { officiosum } \\ \text { iocosum } \\ \text { perniciosum }\end{array}\right\}$ quod $\left\{\begin{array}{l}\text { prodest alicui et nulli nocet : veniale } \\ \text { et fit ex ioco propter licitum solacium : veniale } \\ \text { ex malicia procedit : mortale }\end{array}\right.$

Item martirium sine sanguinis ${ }^{20}$ effusione triplex ${ }^{21}$ est scilicet $\left\{\begin{array}{l}\text { parcitas } \\ \text { largitas } \\ \text { castitas }\end{array}\right\}$ in $\left\{\begin{array}{l}\text { ubcrtate } \\ \text { paupertate } \\ \text { juventute }\end{array}\right\}$ quod habuit $\left\{\begin{array}{l}\text { Job } \\ \text { vidua paupercula } \\ \text { Joseph patriarcha }\end{array}\right.$

Est mors $\left\{\begin{array}{l}\text { corporalis : separatio corporis et anime. Mors et vita a Domino Deo est }\langle\text { Eccli. } 11,14\rangle \\ \text { spiritualis : separatio anime a Domino. Sinite mortuos sepelire mortuos suos }\langle\text { Mt. } 8,22\rangle\end{array}\right.$

Eccli. $41^{22}$ : O mors, quam amara est memoria tua $<$ Eccli. $41,1>$

Mors corporis fit $\left\{\begin{array}{l}\text { necessitate naturali } \\ \text { infirmitate corporali } \\ \text { cffectu matcriali }\end{array}\right\}$ ut in $\left\{\begin{array}{l}\text { in senibus } \\ \text { pueris } \\ \text { peremptis }\end{array}\right.$

$[170 v]$ Est mors $\left\{\begin{array}{l}\text { mortem advocans : dyabolus. De prima et secunda, Osee } 13: \text { O mors, ero mors tua }<\text { Os. } 13,14> \\ \text { mortem generans : peccatum. Deus mortem non fecit }<\text { Sap. } 1,13> \\ \text { etcrnaliter crucians : pcna ctcrna. Ps. : Mors depascet } \cos <\text { Ps. } 48,15> \\ \text { mortem superans : Deus }\end{array}\right.$

${ }^{18}$ fundavit] fudavit sic in $m s$

${ }_{19}^{19}$ Pharao] Pharo sic in $\mathrm{ms}$

${ }^{20}$ sanguinis] saguinis sic in ms

${ }^{21}$ triplex] tripplex sic in ms

${ }^{22}$ Eccli. 41] add. in marg.

Mors anime $\left\{\begin{array}{l}\text { mala : consensus interior } \\ \text { peyor : actus exterior } \\ \text { pessima : peccandi consuetudo }\end{array}\right\}$ et notatur per $\left\{\begin{array}{l}\text { filiam archisinagogi }{ }^{23} \text { in domo } \\ \text { filium vidue in porta } \\ \text { Lazarum in monumento }\end{array}\right.$

Versus :

Mens $<$ mala $\rangle^{24}$, mors intus, malus actus, mors foris, usus tumba ${ }^{25}$

Puella, puer, Lazarus ista notant ${ }^{26}$
Pus

Est manus $\left\{\begin{array}{l}\text { solius Patris : Filius. Ps. : Inveniatur manus tua omnibus inimicis tuis }<\text { Ps. 20, } 9> \\ \text { solius Fily : corporalis. Ibidem : Et foderunt manus meas }<\text { Ps. } 21,17>\end{array}\right.$

(ocius Trinitatis: multiplex, secundum diversos effectus scilicet Scilicet manus $\left\{\begin{array}{l}\text { solitudinis : purgantis. Iob : Manus Domini tetigit me }<\text { Job. } 19,21> \\ \text { potestatis : vindicantis. Difficile est incidere in manus Dei viventis }<\text { Hbr. } 10,31> \\ \text { misericordie : relevantis. Ps. : Cum ceciderit non collidetur }<\text { Ps. } 36,24>\end{array}\right.$

Benignitatis : creantis. Job, Ps. : Manus tue, Domine, fecerunt me <Job. 10, 8, vel Ps. 118, $73>$

Mundus dicitur mare propter $\left\{\begin{array}{l}\text { amaritudinem iniquitatis. Deutcronomio : Uva eorum fellis }<\text { Dt. } 32,32> \\ \text { commocionem perversitatis. Ps. : Mirabiles elaciones maris }<\text { Ps. } 92,4>\end{array}\right.$

et fluctuationem instabilitatis. Id. : Motum autem fluctuum ejus tu mitigas $<$ Ps. 88,10$\rangle$

Negatur Christus $\left\{\begin{array}{l}\text { novissima impugnacione } \\ \text { veritatis occultatione } \\ \text { contraria operacione }\end{array}\right\}$ ut $\left\{\begin{array}{l}\text { Judei, pagani, heretici } \\ \text { Petrus qui negavit Christum ore sed non corde } \\ \text { et falsi christiani }\end{array}\right.$

1 Unde : Ne disperdas David in tituli inscriptionem ${ }^{27}<$ Ps. 56, 1, vel 57, 1, vel 58, $1>$

2 Mt. 26 : Non novi hominem <Mt. 26, 72>

Apostolus : Qui confitetur Christum verbis factis autem negat mendax est $<\mathrm{cf}$. Tit. 1, 16>

Novissima $\left\{\begin{array}{l}\text { mors corporis laboriosa. Ps. : Quis est homo qui vivet et non videbit mortem ? }<\text { Ps. } 88,49> \\ \text { discussio judicis formidolosa. Omnes nos manifestari oportet ante tribunal Christi }<2 \text { Cor. } 5,10>\end{array}\right.$ infernalis punitio periculosa. In inferno nulla est redemptio

\footnotetext{
${ }^{23}$ archisinagogi] archasinagogi sic in ms ante corr.

${ }^{24}$ mala] suppleamus

25 tumba] tuba sic in m.

${ }^{26} \mathrm{cf}$. Hans Walther, Proverbia sententiae latinitatis medii aevi, t. II, nº 14699

${ }^{27}$ inscriptionem] inscriptione sic in $\mathrm{ms}$.
} 
Oves $\left\{\begin{array}{l}\text { debiles et infirme : incipientes } \\ \text { pregantes et fete : proficientes } \\ \text { errantes et vage : convertibiles } \\ \text { stantes et valide : perfecti }\end{array}\right\}$ illis proponatur $\left\{\begin{array}{l}\text { hystoria } \\ \text { tropologia } \\ \text { allegorica } \\ \text { anagogia }\end{array}\right\}$ quia $\left\{\begin{array}{l}\text { facilior } \\ \text { suavior } \\ \text { acutior } \\ \text { excellentior }\end{array}\right.$

1,2 Joh. ult. : Pasce oves meas $<J n .21,17>$. Can. $4^{28}$ : Omnes gemellis et fetibus et sterilis etc. $\langle$ Ct. 4,2$\rangle$

3, 4 Jo. 10 : Et alias oves habeo, que non sunt etc. <Jn. 10, 16> Mt. 10 : Ecce ego mitto vos sicut oves etc. $<$ Mt. 10 16>

Originalia mala $\left\{\begin{array}{l}\text { inpotencia } \\ \text { ignorancia } \\ \text { mali concupiscentia }\end{array}\right\} \operatorname{contra}\left\{\begin{array}{l}\text { potenciam } \\ \text { sapienciam } \\ \text { benevolenciam }\end{array}\right\}$ que $\left\{\begin{array}{l}\text { malo resistit } \\ \text { Deum cognoscit } \\ \text { bonum diligit }\end{array}\right.$

[171r Nota Apostolus dicit 1 ad Tessalo. II capitulo : Sine intermissione orate $<1$ Thes. $5,17>$ Ubi "Glossa, <secundum $>{ }^{29}$ Augustinum : id est certarum horarum orate etc. pro persequentibus vos. Vel sine intermissione orate, id est semper juste vivite et eterna desiderate. Justus enim numquam desinit orare, non desinat justus esse. Semper orat qui semper bene agit. Augustinus super Psalmos: "Ipsum enim desiderium tuum oratio est, et sic si continuum est desiderium, continua est oratio." ${ }^{30}$ Habet omnia Augustinus." ${ }^{31}$

Orandum est $\left\{\begin{array}{l}\text { corde. } 1 \text { Reg. } 1: \text { Anna loquebatur in corde suo }<1 \text { Rg. } 1,13> \\ \text { ore. Ps. : Domine, labia mea aperies et os meum }<\text { Ps. } 50,17> \\ \text { opere. Unde non desinit orare qui non desinit benefacere }{ }^{32}\end{array}\right.$

$\{$ prosperitatis. Ps. : Confitebitur tibi cum benefeceris ei $\langle$ Ps. 48,19$\rangle$

Quidam orant tempore $\{$ adversitatis. Id. : Ad Deum cum tribularer clamavi $<$ Ps. 119,1 $>$

utroque. Id. : Benedicam Dominum in omni tempore $<$ Ps. $33,2>$

\footnotetext{
${ }^{28} 26$ add. $m s$

${ }^{29}$ secundum| suppleamus

${ }^{30}$ Augustinus Hipponensis, Enarrationes in Psalmos, 37,14 (v. 10), transmis par la Glossa ordinaria.

${ }^{31}$ Glossa ordinaria sur 1 Thess. 5, 17. Le paragraphe enticr est ajouté cn marge supćricurc.

${ }^{32}$ cf. Glossa ordinaria sur Lc. 18, 1: "Scmpcr orat qui semper agit bona, nee desinit orare nisi cum desinit iustus essc". Idem sur 1 Thess. 5, 17: "Iustus cnim numquam desinit orare, nisi desinat iustus esse, scmper orat qui semper bene agit".
}

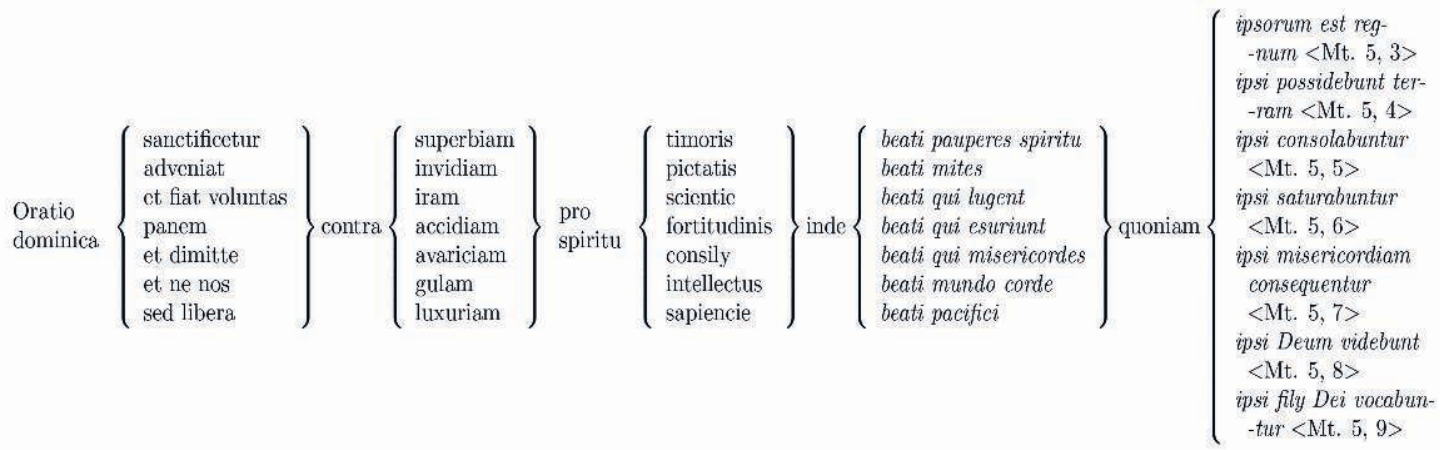

Pueri sunt $\left\{\begin{array}{l}\text { infirmi. Mt. } 18 \text { : Si quis scandalizaverit unum de pusillis hys, qui in me credunt }<\mathrm{Mt} .18,6> \\ \text { fatuosi. Maledictus puer centum annorum }<\mathrm{Is} .65,20> \\ \text { humiles. Mt. } 18: \text { Nisi conversi fueritis, et efficiamini sicut parvuli, etc. }<\mathrm{Mt} .18,3> \\ \text { puri. Pueri, numquid habetis pulmentarium? }<\mathrm{Jn} .21,5>\end{array}\right.$

(nature : omnis homo Augustinus homini. ${ }^{33}$ Mt. : Diliges proximum tuum sicut teipsum $<\mathrm{Mt} .19,19>$

Proximus dicitur ratione $\left\{\begin{array}{l}\text { nature: : omnis : Christus Judeorum. Ps. : Qui locuntur pacem }<\text { Ps. } 27,3>\text { etc. } \\ \text { sanguinis }\end{array}\right.$

(inpensi beneficy : beneficus benefaciat. Luc. : Samaritanus etc. $<$ Lc. $10,33>$

Est potus $\left\{\begin{array}{l}\text { amarus scd saluber. Mt. : Quidem meum bibetis }<\text { Mt. } 20,23> \\ \text { suavis ct saluber }\left\{\begin{array}{l}\text { divine gratic. }{ }^{34} \text { Qui sitit, veniat }<\text { Apc. } 22,17> \\ \text { spiritualis intelligentie. Ps. : Super aquam refectionis educavit me }<\text { Ps. } 22,2> \\ \text { Dominici sanguinis. Mt. : Bibite ex hoc omnes }<\text { Mt. } 26,27> \\ \text { conversionis fratris. Ps. : Cucurri in siti }<\text { Ps. } 61,5>\end{array}\right.\end{array}\right.$

${ }^{33}$ L'ordre des mots pose question. Il semble s'agir d'une citation d'Augustin sur la charité chrétienne : "proximus est omni homini omnis homo" (Augustinus Hipponensis, De disciplina christiana, cap. III, 1. 77, ód. R. Vander Plactse, Turnhout, Brepols 1969 (Corpus Christianorum Series Latina, 46), p. 207-224). L'ordre des mots a-t-il ćté inversé ? S'agit-il d'une mauvaise lecture sur un autre manuscrit ?

${ }^{34} 20$ add. in ms. 
Est pluvia $^{35}\left\{\begin{array}{l}\text { omnibus datur : materialis aqua. Pluit Dominus super bonos et malos }<\text { cf. Mt. } 5,45> \\ \text { per doctores delectatur : doctrina evangelica. Mandabo nubibus meis }<\text { Is. } 5,6> \\ \text { bonis ministratur : gratia divina. Pluviam voluntariam segregabis, Deum, etc. }<\text { Ps. } 67,10> \\ \text { malis reservatur : pena cterna. Pluit super peccatores laqueos }<\text { Ps. } 10,7>\end{array}\right.$

Est panis $\left\{\begin{array}{l}\text { sacramentalis } \\ \text { doctrinalis } \\ \text { eternalis }\end{array}\right\}$ scilicet $\left\{\begin{array}{l}\text { eucaristia } \\ \text { divina Scriptura et ille panis est }\left\{\begin{array}{l}\text { angelorum, Christus transsubstantialis } \\ \text { filiorum, triplex expositio } \\ \text { amicorum, sancta Trinitas }\end{array}\right. \\ \text { visio eterna }\end{array}\right.$

1,2 Unde Ps. : Panem angelorum manducavit homo $\langle$ Ps. $77,25>-$ Mt. : Non est bonum sumere panem $<$ Mt. $15,26>$

3 Luc. : Amice acomoda michi tres panes $<$ Lc. 11, $5>$ et fidem sancte Trinitatis.

Predicatores sunt in celo per $\left\{\begin{array}{l}\text { conversationem. Nostra conversatio in celis est }<\text { Phlp. } 3,20\rangle \\ \text { contemplationem. Paulus raptus in tertium celum }<\text { cf. } 2 \text { Cor. } 12,2-4> \\ \text { celestium predicationem. Celi enarrant gloriam Dei }<\text { Ps. } 18,2>\end{array}\right.$

$[171 \mathrm{v}]$ Querunt quidam Dominum $\left\{\begin{array}{l}\text { et non inveniunt. Queretis me et non invenietis }<\mathrm{Jn} .7,34 \text { vel } 36> \\ \text { et inveniunt sed non retinent. Sinite hos abire }<\mathrm{Jn} .18,8> \\ \text { inveniunt et retinent. Accesserunt et tenuerunt pedes ejus }<\text { Mt. 28, 9> }\end{array}\right.$

Quidam querunt sapientiam $\left\{\begin{array}{l}\text { et non inveniunt quia in ea studere nolunt } \\ \text { et inveniunt sed non diligunt quia pro temporalibus vendunt } \\ \text { ct inveniunt ct diligunt quia ad laudem ctcrne sapicntic querunt }\end{array}\right.$

Primi ab eterna sapientia non assummuntur, sed judicantur et abiciuntur. Secundi assummuntur ut gravius judicentur et precipitentur. Tertii assummuntur ut cleventur et glorificentur.

Refectio $\left\{\begin{array}{l}\text { compaginans : caritas perfecta. Mt. } 11^{\circ}: \text { Venite ad me omnes qui laboratis }<\text { Mt. } 11,28> \\ \text { vires reparans : Eukaristia } \\ \text { refocillans : baptisma. Ps. : Super aquam refectionis }<\text { Ps. } 22,2> \\ \text { satians : perfruitio divina }\end{array}\right.$

${ }^{35}$ pluvia] epula sic in $m s$.

Est rex $\left\{\begin{array}{l}\text { regum : Deus. Et habet in vestimento et in femore }\langle\text { Apc. } 19,16\rangle \\ \text { gentium : impcrator. Reges gentium dominantur eorum }\langle\text { Lc. } 22,25\rangle \\ \text { tenebrarum : demon. Non est nobis colluctatio adversus }\langle\text { Eph. } 6,12\rangle \\ \text { animarum : prelatus. Dum discernit celestes reges }\langle\text { Ps. } 67,15\rangle \\ \text { corporum : cor. Cor regum in manu Dei est }\langle\text { Pr. } 21,1\rangle\end{array}\right.$

Recordatio peccatorum $\left\{\begin{array}{l}\text { suggeritur } \\ \text { inspiratur }\end{array}\right\}$ homini $\left\{\begin{array}{l}\text { a. dyabolo } \\ \text { a. Deo }\end{array}\right\}$ ad ingerendum $\left\{\begin{array}{l}\text { delectationem } \\ \text { desperationem } \\ \text { comprchensionem } \\ \text { humiliationem }\end{array}\right.$

Recordatio peccati quandoque $\left\{\begin{array}{l}\text { ad consensum pravitatis animum inflectit } \\ \text { illicita delectatione memoriam }{ }^{36} \text { aliquatenus inficit } \\ \text { ad contritionem } \operatorname{cor}^{37} \text { emollit } \\ \text { ad gratiarum actionem cor accendit }\end{array}\right\}$ et est $\left\{\begin{array}{l}\text { iniquitatis malorum } \\ \text { infirmitatis incipientium } \\ \text { virtutis proficientium } \\ \text { felicitatis perfectorum }\end{array}\right.$

2,3 Ps. : Torrentes iniquitatis conturbaverunt me. $\langle$ Ps. $17,5>$ Id. : Lavabo per singulas noctes lectum meum. $\langle$ Ps. $6,7>$

4 Gratia Deo qui dedit nobis vicloriam per Ihesum Christum $\langle 1$ Cor. 15, 57>

Superbia $\left\{\begin{array}{l}\text { ascriptionis } \\ \text { jactancie } \\ \text { emulacionis } \\ \text { presumptionis }\end{array}\right\}$ quando $\left\{\begin{array}{l}\text { quod a Deo habemus a Deo non recognoscimus } \\ \text { a Deo recognoscimus sed merita nostra jactamus } \\ \text { simulamus habere quod non habemus ut magni videamur } \\ \text { in eo nos alys preferrimus in quo eis pares vel minores sumus }{ }^{38} \\ \text { unde : ex se, pro meritis, falso, plus omnibus ambit. }{ }^{39}\end{array}\right.$

Est sapientia $\left\{\begin{array}{l}\text { Dei } \\ \text { carnis } \\ \text { mundi }\end{array}\right\}$ hujus studium est $\left\{\begin{array}{l}\text { in lege Dei meditari } \\ \text { in carnalibus delcetari } \\ \text { in secularibus negociari }\end{array}\right.$

1, 2. 3 Omnis sapientia a Domino Deo est <Eccli. 1, 1>. Sapientia carnis inimica est Deo <Rom. 8. 7>. Sapientia hujus mundi stultitia est aput Deum $\langle 1$ Cor. 3,19$\rangle$

Sapientia. Dei cst duplex scilicet naturalis ct accidentalis.

37 ejus add el exp. in m.
37 memoriam] memoria sic in ms.
38 minores sumus minrores summ

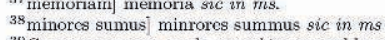

${ }^{39} \mathrm{Cc}$ vers commun sur la superbia reprond les quatre aspects des arrogants ćnumćrćs par Crégoiro le Grand. Cf. Gregorius Magnus, Moralia in Job, ćd. M. $\Lambda$ driacn, Turnhout, Brepols, 1985 (Corpus. Christianorum Series Latina, 143B), lib. XXIIT, cap. VI, § 13, p. 1153-ō4. 
$[172 r]$ Sanguinis Christi effusio in $\left\{\begin{array}{l}\text { circumcisione } \\ \text { sudorc } \\ \text { et flagellatione } \\ \text { mortui lanceatione }\end{array}\right\}$ fuit in $\left\{\begin{array}{l}\text { cxemplum tempcrancic } \\ \text { signum obediencie } \\ \text { remedium discipline } \\ \text { spectaculum memorie } \\ \text { sacramentum eucaristie }\end{array}\right.$

Sunt sagitte $\left\{\begin{array}{l}\text { livoris : insidie iniquorum. Paraverunt sagittas suas in }\langle\text { Ps. } 10,3> \\ \text { timoris : predicatores. Misit sagittas suas et dissipavit eos }<\text { Ps. } 17,15> \\ \text { doloris : penalitates presentes. Quoniam sagitte tue infixe etc. }<\text { Ps. } 37,3> \\ \text { amoris : verba Domini. Sagitte tue accule }<\text { Ps. } 44,6>\end{array}\right.$

Semen malum $\{$ prava operatio. Ps. : Fructum eorum de terra perdes, et semen eorum $<$ Ps. $20,11>$ $\{$ perversa generatio. Ysa. : Ve genti peccatrici et semini nequam $<$ Is. 1, $4>$ Semen bonum seminatum $\left\{\begin{array}{l}\text { pro nobis : ct Filius Dei. Gen. : In semine tuo benedicentur omnes gentes }<\text { Gn. } 22,18> \\ \text { de nobis : apostoli Domini. Ysa : Nisi Dominus exercituum reliquisset nobis semen }<\text { Is. } 1,9> \\ \text { in nobis : verbum Dei. Luc. : Semen est verbum Dei }<\text { Lc. } 8,11> \\ \text { a nobis : bona operatio. Que seminaverit homo, hec et metet }<\text { Gal. } 6,8>\end{array}\right.$

Status $\left\{\begin{array}{l}\text { penitentic } \\ \text { justitie } \\ \text { glorie }\end{array}\right\}$ in quo $\left\{\begin{array}{l}\text { reducimur } \\ \text { deducimur } \\ \text { educimur }\end{array}\right\}$ de $\left\{\begin{array}{l}\text { invio in viam, de tencbris ad luccm } \\ \text { mansione in mansionem, de virtute in virtutem } \\ \text { exilio in patriam, de labore in requiem }\end{array}\right.$

Primus status sanat. Secundus conservat. Tertius consummat. Unde Dominus : Ecce, ego hodie et cras demonia ejicio, sanitates perficio et tertia die consummor. $<$ Lc. $13,32>$

$\int$ patris equalitate. Ps. Dixit Dominus Domino meo : sede a dextris $\langle$ Ps. 109,1$\rangle$ assumpta hurnilitate. Mt. 5 : Et cum sedisset accesserunt ad eum $\langle$ Mt. $5,1>$

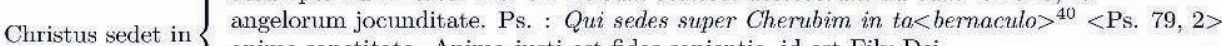
anime sanctitatc. Anima justi est fides sapicntic, id cst Fily Dei

celorum sublimitate. Ps. : Paravit in celo sedem suam $\langle$ Ps. 102, 19> judiciaria potestate. Mt. 25: Tunc sedebit Filius hominis $<$ Mt. 25, 31>

${ }^{40}$ Le manuscrit donne "in ta.", que nous proposons de développer en "in tabernaculo" ; d'après la Vulgate, on attendrait "manifestare".

Est serpens $\left\{\begin{array}{l}\text { qui seducitur : homo. Et furor illis secundum similitudinem serpentis }<\mathrm{Ps} .57,5> \\ \text { cujus caput conteri precipitur : suggestio. Ipsa conteret caput tuum }<\mathrm{Gn} .3,15> \\ \text { cujus caput conservari consulitur : fides. Estote prudentes sicut serpens }<\mathrm{Mt} .10,16> \\ \text { qui salubriter inspicitur : Christus. Serpens cneus in palo }<\text { cf. Num. } 21>\end{array}\right.$

Itcm Deus anime subtrahit
consolationes multiplici de causa, ut $\left\{\begin{array}{l}\text { potentie Dei utilitas cognoscatur } \\ \text { propria infirmitas videatur } \\ \text { eterne separationis timor incutiatur } \\ \text { immoderatis anime expensis parcatur }\end{array}\right\}[172 \mathrm{v}]$ ut $\left\{\begin{array}{l}\text { ipse Deus diligencius requiratur } \\ \text { gratancius excipiatur inventus } \\ \text { exceptus cautius custodiatur } \\ \text { nostre dilectionis fictio deprehenditur } \\ \text { potiora carismata largiatur }\end{array}\right.$

Signa vite : si homo $\left\{\begin{array}{l}\text { sentit } \\ \text { spirat } \\ \text { movetur } \\ \text { cibum appetet } \\ \text { calet }\end{array}\right\}$ spiritualiter per $\left\{\begin{array}{l}\text { contritionem } \\ \text { confessionem } \\ \text { satisfactionem } \\ \text { predicationem } \\ \text { dilectionem }\end{array}\right.$

Sensus sacre Scripture $\left\{\begin{array}{l}\text { litteralis } \\ \text { allegoricus } \\ \text { moralis } \\ \text { anagogicus }\end{array}\right\}$ docet quod $\left\{\begin{array}{l}\text { sciendum } \\ \text { credendum } \\ \text { agendum } \\ \text { appetendum }\end{array}\right\}$ in $\left\{\begin{array}{l}\text { rei geste hystoria } \\ \text { militante Ecclesia } \\ \text { vita Christiana } \\ \text { triumphante Ecclesia }\end{array}\right.$

Versus :

Littera gesta docet, quid credas allegoria

Moralis quid agas, quid speras anagogia ${ }^{41} 42$

Tres ultimi sensus dicuntur mistici a mistcrio.

Terra est quam $\left\{\begin{array}{l}\text { terrimus : elementum. In principio creavit Deus celum et terram }<\mathrm{Gn} .1,1> \\ \text { serimus : peccatum. Terram comedes }{ }^{43} \text { omnibus diebus vite tue }<\mathrm{Gn} .3,14> \\ \text { gerimus : corpus humanum. Terra tradita est in manus impy }<\text { cf. Job. } 9,4> \\ \text { querimus : celum empireum }{ }^{44} \text {. Credo videre bona Domini }<\text { Ps. } 26,13>\end{array}\right.$

41 anagogia] anagoga sic in ms.

${ }^{42}$ Vers mnémonique attribué à Augustin de Dacie (REF A CHERCHER). cf. Hans Walther, Proverbia sententiae latinitatis medii aevi, t. II, ${ }^{\circ} 13899$

43 comedes] commedes sic in m.s.

44 empireum] epirreum sic in m.s. 
Est tabernaculum malorum $\left\{\begin{array}{l}\text { in quo spem ponunt } \\ \text { qui deserviunt } \\ \text { quod constituunt }\end{array}\right\}$ scilicet $\left\{\begin{array}{l}\text { mundus } \\ \text { corpus } \\ \text { malorum conventus }\end{array}\right.$

1,2 Ps. : Pro iniquitate vidi tentoria Ethiopye $<$ Hab. 3, 7>. Apostolus: Habernus allare de quo non habent edere qui tabernaculo deserviunt $<$ Hbr. $13,10>$.

$3 \quad$ Ps.: Elegi abjectus $<$ Ps. $83,11>$ etc.

Est tabernaculım justorum $\left\{\begin{array}{l}\text { quod excolunt } \\ \text { in quo proficiunt } \\ \text { ad quod tendunt }\end{array}\right\}$ scilicet $\left\{\begin{array}{l}\text { caro humana } \\ \text { presens Ecclesia } \\ \text { celestis patria }\end{array}\right.$

1,2 Instat dissolucio tabernaculi mei <ef. 2Ptr. 1,14>. Ps.: Domine, quis habitabii in tabernaculo $<$ Ps. $14,1>$ etc.

3 Apoc. 21 : Ecce tabernaculum Dei cum hominibus et habitabit cul eis $\langle$ Apc. 21,3>

Item est tabernaculum solius Christi corpus ejus. Ps. : In sole posuit tabernaculum $\langle$ Ps. 18, 6>

$\left(\begin{array}{l}\text { maturalis. Mar. } 14: \text { Et cepit panem et benedicens fregit Ihesus <Mc. 14, 22> } \\ \text { humanus, quem habuit. Petrus negando Christum }\end{array}\right.$

Est timor $\left\{\begin{array}{l}\text { mundanus. Pylatus cum audisset hos sermones magis timuit }\langle\mathrm{Jn} .19,13 \text { et } 8\rangle \\ \text { servilis. Letato }\end{array}\right.$

inicialis. Inicium sapientie timor Domini $\langle$ Ps. 110,10 vel Eccli. $1,16>$

filialis : Venite fily, audite me, timorem Domini docebo $<$ Ps. $33,12>$ etc.

reverentialis. Timete Dominum onnes sancti $\langle$ Ps. 33,10$\rangle$. "Quem tremunt potestates" 45 etc.

(Christum obsidentes : Judei. Thauri pingues ${ }^{46}$ obsederunt me $\langle$ Ps. 21, 13>

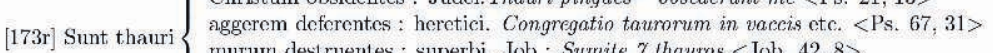
murum destruentes : superbi. Job: Sumite 7 thauros $\langle$ Job. 42,8$\rangle$

Ecclesiam construentes : Patres antiqui. Thauri mei et altilia mea etc. $<$ Mt. 22, 4>

$\left\{\right.$ clacionis : Babclon ${ }^{47}$. Gen. XI : Venite, faciamus nobis civitatem et turrim ctc. $\langle\mathrm{Gn} .11,4\rangle$

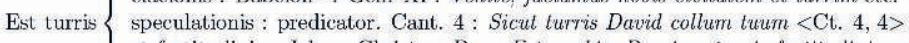

et fortitudinis : Jehsus Christus. Ps. : Esto nobis, Domine, turris fortitudinis $\langle\mathrm{cf} \text {. Ps. } 60,4\rangle^{48}$

${ }^{45}$ Próface do la messe. Missalc Romanum. Ordo Missac cum populo, pracf. IV do Quadr.; Pracf. I de B. Maria V; pracf. de S. Joseph ; Pracf. communis II ; In cxaltationc s. Crucis, l'raef. propr.

${ }_{46}^{46}$ pingucs] pigmes sic in $m s$.

${ }^{17}$ Babelon sic in ms.

${ }^{48} \mathrm{La}$ citation est cn fait dérivéc non des Psaumcs dircetement, mais de la liturgic. Ronć-Jcan Hesbort, Corpus antiphonalium Officir, nr. 6673

\footnotetext{
furoris : tyrannus vel demon. Virga furoris mei, Assur ${ }^{49}<$ Is. $10,5>$

blande correctionis: levis castigatio. Virga tua et baculus tuus $\langle$ Ps. 22,4$\rangle$

scvere animadversionis : regalis potestas Domini.Rege eos in virga ferrea $<$ Ps. 2, 9, vel Apc. 2, 27, vel Apc. 19, 15 $>$

Virga $\{$ vigilie pastoralis : presul. Virgam vigilantem ego video $<\mathrm{Jr} .1,11>$

dircctionis : norma mundi. Virga directionis virga regni tui $\langle$ Ps. 44,7$\rangle$

virtutis : Christus. Virga virtutis tue. $\langle$ Ps. 109, $2>$

fructificationis : beata Virgo. Egredietur virga de radice Yesse $<\mathrm{Jr} .11,1\rangle$
}

Est visio $\left\{\begin{array}{l}\text { cognitionis } \\ \text { animadversationis } \\ \text { miscrationis } \\ \text { approbationis }\end{array}\right\}$ qua Deus $\left\{\begin{array}{l}\text { videt omnia } \\ \text { punit mala } \\ \text { pic respicit miscros } \\ \text { approbat bonos }\end{array}\right.$

Vigilat $\left\{\begin{array}{l}\text { Deus } \\ \text { justus } \\ \text { prelatus } \\ \text { malus vel dyabolus }\end{array}\right\} u t\left\{\begin{array}{l}\text { protegat. Ps. : Non dormitabit neque }\langle\text { Ps. } 120,4>\text { etc. } \\ \text { in se proficiat. Vigitale et orate ne intretis }<\text { Lc. } 22,40\rangle \\ \text { in suis proficiat.Pastores erant vigilantes }<\text { Lc. } 2,8\rangle \\ \text { noceat. Tanquam leo rugiens circuit }<1 \text { Ptr. } 5,8>\end{array}\right.$

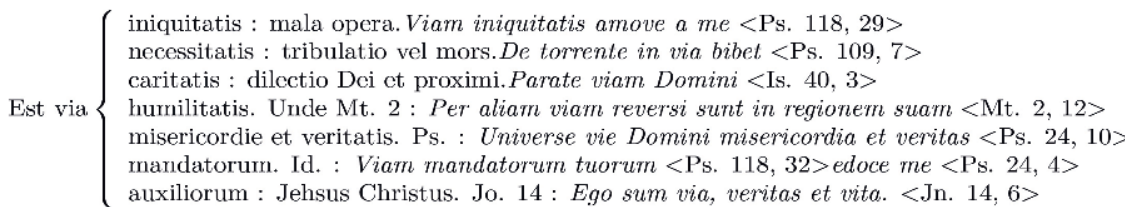

Sunt vie $\left\{\begin{array}{l}\text { dure } \\ \text { recte } \\ \text { gloriose }\end{array}\right\}$ in statu $\left\{\begin{array}{l}\text { penitentie: dolor contritionis, pudor confessionis, labor satisfactionis } \\ \text { justitie.Servate precepta < In. 14, 15>quantum ad Deum, seipsum, et proximum } \\ \text { glorie. Inmortalitas sine lesione, cognicio sine errore, dilectio absque rctardacione }\end{array}\right.$

1 Ego custodivi vias duras $\langle$ Ps. 16,4$\rangle$

2 Sap. 10 : Justum deducit Dominus per vias rectas $<$ Sap. 10, $10>$

3 Sicut exaltantur celi a terra, ita exaltate sunt vie mee a vys vestris $<$ Is. 55, 9>

${ }^{49}$ Assur] Asur sic in $m s$. 
[173v] Christus cst $\left\{\begin{array}{l}\text { via } \\ \text { veritas } \\ \text { vita }\end{array}\right\}$ in $\left\{\begin{array}{l}\text { exemplo qua } \\ \text { promisso per quam } \\ \text { regno ad quam }\end{array}\right\}$ itur, quam $\left\{\begin{array}{l}\text { instruimur } \\ \text { alliciamur } \\ \text { glorificabimur }\end{array}\right.$

luxurie vel vanitatis. Nolite inebriari vino, in quo est luxuria $<$ Eph. $5,18>$

falsitatis vel amaritudinis : doctrina heretica. Caupones tui miscent aqua vinum $<\mathrm{Is} .1,22>^{50}$

austeritatis : vetus lex. "Vimum enecat parvulos."

compunctionis. Potasti nos vino compunctionis. $\langle$ Ps. 59,5 $>$ Samaritanus infudit oleum et vinum $<$ cf. Le. 10,34>

Est vinum 2 contemplationis. Ioh. 2 : Servasti vinum bonum usque adhuc $\langle$ Jn. 2,10$\rangle$

divine fruitionis. Unde: Non bibam de genimine vitis <Mc. 26,39 vel Mc. $14,25>$ etc.

exultationis : eukaristia. Ei "vinum letificat cor hominum" "23

ct future tribulationis. Et crit tanquam potens crapulatus a vino $\langle$ Ps. 77,65$\rangle$

eterne glorificationis. Calix meus inebrians, quam preclarus est $\langle\mathrm{Ps} .22,5\rangle$

castitatis. Vinum germinat virgines <ef. Zach. 9, 17> ${ }^{54}$

Ps. 84 : Misericondia et veritas obviaverunt sibi ; justitia et pax oseulate sunt. $<$ Ps. $84,11>$ Hic commitantur 4or virtutes que quasi cum Deo cooperate sunt in principio creationis mundi et post hominis creationem et frequenter in gubernacione seculi.

$\left\{\begin{array}{l}\text { veritatem: ea que ab eterno disposuerat opere complevit } \\ \text { misericordiam : angelicum chorum per superbiam lapsum per hominem de lutea materia factum reparavit }\end{array}\right.$

1 Deus per pacem: carnem et animam que valde sunt dissimilia satis concorditer conjunxit justiciam : dignius animal indignioribus prestituit scilicet Adam cui subjecit creaturas hujusmodi. Unde Ps. : Omnia subjecisti sub pedibus etc. $\langle$ Ps. $8,8>$

veritatem communicationem Ade factam complevit.Quacumque die conversus etc. $<$ Ez. $33,12>$

(justiciam : magis peccantem magis punivit, minus peccantem minus, ut patct Gn. $3^{\circ}$

2 Deus per $\{$ pacem : hominem qui per inobedienciam ceciderat ad obedienciam revocavit.

misericordiam : hominem qui semper duraturus erat in miseria hujus seculi necessitati moriendi subjecit.Ps. : Quis est homo qui vivet et non videbit ctc. $<$ Ps. $88,49>$

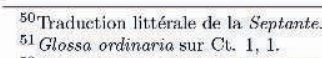

$\int$ veritatem omnia que a prophetis sunt opere complet

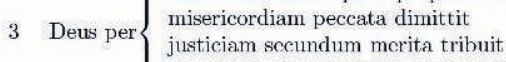

pacem ab adversantibus in se confidentes protegit

Venti $\left\{\begin{array}{l}\text { nescitur unde veniunt } \\ \text { validi sunt } \\ \text { glacicm dissolvunt } \\ \text { in altum ascendunt }\end{array}\right\}$ sic predicatores $\left\{\begin{array}{l}\text { Qui producit ventos de thesauris suis }<\text { Ps. } 134,7> \\ \text { Neque mors neque vita }<\text { Rom. } 8,38> \\ \text { Flabit spiritus ejus, et fluent aque }<\text { Ps. } 147,7> \\ \text { Apostolus: Sive sobry sumus }[174 \mathrm{r}] \text { sive excedimus a } \text { Deo }^{5.5}<2 \text { Cor. } 5,13>\text { Sobrii }{ }^{56} \text { appellat } \\ \text { qui minora propter minores docet. Excedentes vocat subtilia instruentes. }\end{array}\right.$

Vell ab ove sive a pelle vel carne separatur materia absque omni vicio carnalitatis

Vellus $\{$ sine lesione segregatur. Christus de vellere sine corruptione indumentum induit

in recipiendo sero emittendo aquam non dissipatur

Maria virgo in conceptu, in partu, post partum.

Visus obscuratur per $\left\{\begin{array}{l}\text { tencbras, id cst por ignoranciam } \\ \text { defluentes humores, id est terrenas delectationes } \\ \text { nimiam claritatem, id est nimiam intellectus curiositatem }\end{array}\right.$

2,3 Ps. : Obscurentur oculi eorum ne videant $<$ Ps. $68,24>\operatorname{Pr}$ : : Scrutator majestatis opprimetur a gloria $\langle$ Pr. 25,27$\rangle$

$\begin{array}{lll}\text { Annus } & \text { Confessio } & \text { Diligere } \\ \text { Altare } & \text { Casus } & \text { Dilectionis g } \\ \text { Apostoli dicuntur montes } & \text { Calix } & \text { Diligendi orc } \\ \text { Ascendere Domini } & \text { Canis } & \text { Deceptio } \\ \text { Audire Dci } & \text { Calciamentum multiplex } & \text { Discretc }^{57} \\ \text { Arbor } & \text { Calciamentum muniens } & \text { Dextera } \\ & \text { Clamor } & \\ \text { Bonorum differentia } & & \text { Elementum } \\ & \text { Domus } & \text { Etas } \\ & \text { Digitus } & \text { Esse Domini }\end{array}$




\section{Annexe}

\section{Description détaillée du manuscrit Munich, Bayerische Staatsbibliothek, clm 4784}

Allemagne du sud, deuxième moitié du $\mathrm{XV}^{\mathrm{e}}$ siècle (après 1449). Donné en 1505 à l'abbaye bénédictine de Benediktbeuern (Bavière) ${ }^{32}$.

\section{Description codicologique}

Papier, $155 \times 215 \mathrm{~mm}$, cadre de réglure : $102 \times 158$ $\mathrm{mm}$.

Le manuscrit a subi de malheureuses mutilations depuis la réalisation de la reproduction photographique aujourd'hui publiquement disponible en ligne. Si l'on en juge par les images des microfiches, avant ces modifications le manuscrit devait comporter 314 fol. (dont les quatre derniers blancs), numérotés en chiffres arabes de 1 à 313 par une main médiévale, à partir du troisième feuillet, avec le numéro 255 manquant à cause d'une erreur de numérotation. Après la réalisation de ces photos, le fol. 277 selon la numérotation médiévale, blanc, a été retiré, ainsi que deux feuillets blancs à la fin du manuscrit (312 et 313 dans la numérotation médiévale) et le feuillet 311 selon la numérotation médiévale est désormais collé au contre-plat inférieur. Après que ces feuillets blancs aient été retirés, le manuscrit a reçu une nouvelle numérotation, moderne, en bas à droite des folios. Celle-ci est identique à la numérotation médiévale jusqu'au fol. 254, puis présente une différence de - 1 avec celle-ci à partir du folio suivant et jusqu'au fol. 276 / 275. Le fol. 277 (numérotation médiévale) ayant été retiré, la numérotation moderne accuse un retard de 2 par rapport à la numérotation médiévale à partir du fol. 278 / 276. La numérotation moderne se termine à 308 , sur le feuillet qui porte la numérotation médiévale 310 .

Reliure de cuir beige avec décor estampé. Traces de cornières, d'un décor floral métallique au centre, et de deux fermoirs.

32. Je dois cette description codicologique, et tout particulièrement la collation des cahiers au Dr. Victoria Smirnova, qui a eu la gentillesse de bien vouloir examiner ce manuscrit à Munich. Je tiens à lui exprimer ici mes plus vifs remerciements pour son aide.
Cahiers : 26 cahiers, dont les limites sont indiquées ci-après selon la numérotation moderne. Quinze cahiers de 12 folios (fol. Ir-10v, pas de réclame; fol. 11r-22v, réclame; fol. $23 \mathrm{r}-34 \mathrm{v}$, réclame; fol. 35r-46v, réclame; fol. 47r-58v, réclame; fol. 59r-70v, réclame; fol. 71r-82v, réclame; fol. 83r-94v, réclame; fol. 95r-106v, réclame; fol. 107r-118v, réclame; fol. 119r-130v, réclame; fol. 131r-142v, réclame; fol. 143r-154v, réclame; fol. 155r-166v, pas de réclame; fol. 167r-178v, réclame); un cahier de 14 folios (fol. 179r-192v, pas de réclame); un cahier de 12 folios (fol. 193r-204v, réclame); un cahier de 10 folios (fol. 205r-214v, réclame); quatre cahiers de 12 folios (fol. 215r-226v, réclame; fol. 227r-238v, réclame; fol. 239r-250v, réclame; fol. 251r-262v, réclame); un cahier de 13 (14 - 1) folios (fol. 263r-275v, pas de réclame, amputé du dernier folio blanc avant l'ajout de la numérotation moderne, entre les fol. 275 et 276 actuels) ; un cahier de 12 folios (f. 276r-287v, réclame); un cahier de 12 folios (fol. 288r-299v, réclame); un cahier de 9 (12 - 3) folios (fol. 300r-308v).

\section{Description du contenu}

Nota bene: pour cette description, j'ai travaillé exclusivement sur la reproduction du manuscrit disponible en ligne, consistant en la numérisation en niveaux de gris de microfiches. Cette reproduction étant de fait le moyen le plus accessible pour la consultation du manuscrit, j'ai privilégié ci-dessous la numérotation médiévale des folios, seule présente sur ces images. J'ai cependant indiqué l'équivalent en numérotation moderne, ajoutée depuis sur le manuscrit, lorsque celle-ci diverge de la médiévale (à partir du fol. 255).

1. Notes sur les mérites respectifs des "docteurs" païens et chrétiens : fol. Ir.

fol. Iv blanc.

2. Table des matières médiévale : fol. IIr-IIv

3. [Jean Gerson?], Tractatulus de bono modo vivendi secundum Deum ad omnes fere status hominum ordinatus : fol. $1 \mathrm{r}-2 \mathrm{v}$

- Inc. : Ne potentes per potentiam suam subditos suos opprimant...

- Expl. : ... et frequenter premia paradisi et tormenta inferni cogitent.

- Biblio : édité dans Jean Gerson 1971, nº 399.

4. [Mirabilia Rome] De mirabilibus antiquis alme urbis Rome : fol. $3 \mathrm{r}-7 \mathrm{v}$ 
- Inc. : Sicut scribit Orosius in cronica sua quod tempus quo Roma incepit...

- Expl. : ... in monte Vaticano ante sanctum Petrum cernitur. Explicit tractatus de mirabilibus Rome.

- Biblio : Miedema 1996. Cf. Augsburg, Staats- und Stadtbibliothek, $4^{\circ}$ Cod 238, fol. 82r-90v (Gehrt 2005, p. 105); Jena, Thüringer Universitäts- und Landesbibliothek, Ms. Sag. o. 2, fol. 385-389v et 430-435 (Klein-Ilbeck \& Ott, 2009); et Yale University, Beinecke Library, MS. 762, fol. 1r-5v (description en ligne: http ://hdl.handle.net/10079/ bibid/9868084)

5. De patriarchis (Extraits du Provinciale Romanum): fol. $7 \mathrm{v}$

- Inc. : Octo sunt patriarche, primus ac major...

- Expl. : ... qui nunc dicitur civitas papalis.

6. [Traité sur le couronnement et l'élection des rois et empereurs Chrétiens]

6a. De regibus Christianis : fol. $8 \mathrm{r}$

- Inc. : De regibus Christianis quorum quidam sunt coronati...

- Expl. : ... et non sunt plures reges Christianorum nisi fierant de novo.

6b. De imperatoribus : fol. $8 \mathrm{v}-9 \mathrm{r}$

- Inc. : Imperatores Christiani sunt duo...

- Expl. : ... omnia que videmus nostra sunt.

6c. De imperatore Constantinopolano : fol. 9r

- Inc. : Imperator constantinopolitanus non fit per electionem sed per successionem...

- Expl. : ... sicut et aly reges Christiani religionis fily. 6d. Electio ducis Venetorum : fol. 9r

- Inc. : Duce Venatorum (sic) mortuo conciliary...

- Expl. : ... in concordia fuerint in eligendo. Ipsi autem sicut electi 41 ducem eligunt.

- Biblio : Texte édité en partie par Werminghoff 1903.

7. [Liste de titres de cardinal, extraits du Provinciale Romanum] : fol. 9v-10r

- Inc. : Tituli presbiterorum cardinalium sunt $28 \ldots$

- Expl. : ... Ostiensis, Vellerensis, Portunensis (sic), sancte Rufine, Albanensis, Sabinensis, Tusculanensis, et Penestrinensis.

fol. 10v blanc

8. Jacques de Voragine, Sermo brevis in die Parasceves: fol. $11 \mathrm{r}-14 \mathrm{v}$

- Thema: Inspice et fac secundum exemplum quod tibi monstratum est. Exo. 25. <Ex. 25, 40>

- Inc. : Christus est tanquam liber exemplaris...

- Expl. : ... fidem in illo triduo firmiter tenuit.

- Biblio: Schneyer 1969-90, vol. 3, p. 244, Jacobus de Voragine $n^{\circ} 284$. Edité dans : Iacopo da Varazze 2005, p. 495-500. Texte disponible en ligne sur le portail Sermones.net. Nota : le sermon, tel qu'il est connu dans les Sermones Quadragesimales, comporte 10 parties. Ce texte lui en ajoute 3, à partir du milieu du fol. $13 \mathrm{v}$

9. [Historia gestorum Christi], sous le titre Concordia et ordo hystoriarum evangelicarum, suivie d'une note sur le dimanche des Rameaux : fol. 15r-27r

- Inc. : In principio erat verbum et verbum erat aput Deum et Deus erat verbum. Cum autem per verbum omnia facta essent....

- Expl. : ... eos qui scribendi sunt libros.

- Biblio: Stegmüller 1950-80, nr 4567. Ce traité a parfois été attribué à Jean Hus, et a été édité parmi ses Opera omnia. Cette attribution semble toutefois erronée. Voir : Bartoš 1948, p. 98 (je remercie le Dr. Jindřich Marek pour cette référence).

10. [Annunciatio festi in ebdomada ante festum pasce et quod Christus fecerit qualibet feria] : fol. $27 v-28 v$

- Inc. : Ad annuntiandum sanctissime future septimane...

- Expl. : ... ut digni efficiamur eterna redemptione prestante Domino nostro Jhesu etc.

11. Nicolas de Dinkelsbühl, Sermo magistri Nico. Dinck De cena Domini : fol. 29r-3lr

- Inc. : Ut plus appropinquemus ad hystoriam Passionis...

- Expl. : ... viaticum sustentationem animarum. Item plura et multa alia de hoc sacramento vide in tractatu ejusdem doctoris de eukaristia, scilicet Caro mea.

- Bibliographie: Madre 1965, p. 143. Hödl \& Koch 1999, N.v.D.40.

12. Nicolas de Dinkelsbühl, Sermo de assumptione Beate Marie Virginis, 2 : fol. 31v-39r

- Inc. : Sicut beatus Augustinus in principio...

- Expl. : ...videamus assistere unigenito filio tuo Domino nostro Jhesu Christo Qui cum Patre et Spiritu sancto vivit unus Deus in secula benedictus.

- Biblio: Madre 1965, p. 222. Hödl \& Koch 1999, N.v.D.173.

13. [Nicolas de Dinkelsbühl, Sermo de assumptione Beate Marie Virginis, 1] : fol. 39r-42r

- Thema: Intravit Jhesus in quoddam castellum <Luc. $10,38>$

- Inc. : cuius nomen Lucas non meminit, sed Johannes exprimit vocans Bethania...

- Expl. : ... pro retributione suscepta est in celi pallacio.

- Biblio: Madre 1965, p. 221. Hödl \& Koch 1999, N.v.D.172.

14. [Nicolas de Dinkelsbühl, Sermo de assumptione Beate Marie Virginis, 3] : fol. 42r-51r 
- Thema : Maria optimam partem elegit, ita scribitur Luc. $10<$ Lc. 10, 42>

- Inc. : et legitur in evangelio hodierno...

- Expl. : sue gratie munera largiatur Jhesus Christus filius tuus qui est Deus super omnia benedictus in secula, amen.

- Biblio: Madre 1965, p. 224. Hödl \& Koch 1999, N.v.D.174.

15. [Nicolas de Dinkelsbühl], Sermo de nativitate Beate Marie Virginis, 2 : fol. 51r-56r

- Thema : Liber generationis Ihesu Christi filii David filii Abraham, Mt. $1^{\circ}$. <Lt. 1, 1>

- Inc. : Locuturi et audituri verbum Dei...

- Expl. : ... Christum mente quam carne gestasset.

- Biblio : Madre 1965, p. 228. Hödl \& Koch 1999, N.v.D.177.

16. [Nicolas de Dinkelsbühl], Sermo de nativitate Beate Marie Virginis, 1 : fol. 56r-64v

- Thema : Maria optimam partem elegit que non auferetur a beata Virgine... Luc. 10. <Lc. 10, 42>

- Inc. : Omnipotens Dominus in multis excellentys et prerogativis virginem Mariam...

- Expl. : et in operibus bonis quibus mer<e >amur vitam eternam quod nobis concedat Marie Filius Dominus noster Jhesus Christus qui cum Patre et Spiritu sancto vivit et regnat unus Deus in secula benedictus, amen.

- Biblio : Madre 1965, p. 227. Hödl \& Koch 1999, N.v.D.176.

17. Nota hic de nominibus beate Virginis sumptis a similitudi<ni $>$ bus rerum tam naturalium quam artificialium : fol. 65r-69r

- Inc. : Nunc sciendum quod ipsa beata Virgo dicitur archa Testamenti...

- Expl. : ... item virge percutienti, Jer. : virgam vigilantem ego video etc.

18. [Nota - quare sabbatum celebratur in honore Beate Marie Virginis] : fol. 69r

- Inc. : Item nota, veneramur beatam Virginem in sabbato propter quinque rationes. Primo quia dies hec est requiei...

- Expl. : ... $5^{\text {to }}$ quia in hac die grex pusillus dum desperavit beata Virgo fortiter stetit.

- Cf. Hildesheim, Dombibliothek, Hs. J 88, fol. 7v (Giermann, Härtel \& Arnold 1993, p. 241).

19. Concordancie Beate Virginis Marie : fol. $69 \mathrm{v}-79 \mathrm{v}$

- Inc. : Beata Virgo comparatur celo. Celum dicitur quasi casa elyos...

- Expl. : ...quod ipse prestare dignetur Ihesus Christus amen

- Biblio : Stegmüller, Repertorium Biblicum, vol. 6, p. 155 , nr. 8879
20. [Sermo de visitatione beate Virginis] : fol. $80 \mathrm{r}-82 \mathrm{v}$

- Thema : Exurgens autem Maria abiit in montana etc. Luce primo. <Lc. 1, 39>

- Inc. : In istis verbis septem per ordinem tanguntur...

- Expl. : ... ista maledictio fili mi. Exemplum de Theopholo (sic) qui se ipsum dedit dyabolo etc.

- Cf. Augsburg, Staats- und Stadtbibliothek, $2^{\circ}$ Cod. 398, fol. 142v-144r (Wolf Gehrt, Die Handschriften der Staats- und Stadtbibliothek Augsburg $2^{\circ}$ Cod 251 400e, Wiesbaden, Harrassowitz, 1989 (Handschriftenkataloge der Staats- und Stadtbibliothek Augsburg, Bd. 4).

21. [Sermo] : fol. $82 \mathrm{v}-85 \mathrm{v}$

- Thema : Afferamus ad nos archam federis Domini et veniat in medium nostri ut salvet nos de manu inimicorum nostrorum, I Reg. 4. <l Rg. 4, 3>

- Inc. : Verba proposita pertinere possunt ad universalem populum Christianum...

- Expl. : ... gratiarum ejusdem superfluentia in gratia plena. Quere alibi additionem ad illa duo membra in tractatu super Ave Maria.

22. [Nicolas de Dinkelsbühl], Sermo de sancto Johanne Baptista : fol. 86r-9lr

- Thema : Quis putas puer iste erit, ita scribitur Luc. $1^{\circ}$. $<$ Lc. 1, 66>

- Inc. : Cum parentes et cognati ac vicini beati Johannis Baptiste vidissent...

- Expl. : ... de virtute in virtutem proficere donec videamus Deum deorum in Syon celesti, quo nos perducat qui sine fine regnat in secula seculorum amen.

- Biblio: Madre 1965, p. 238. Hödl \& Koch 1999, N.v.D.184.

23. [Nicolas de Dinkelsbühl], Sermo de sancta Maria Magdalena : fol. 91v-95v

- Thema: Rogabat Jhesum quidam Phariseus ut manducaret cum illo et ingressus domum Pharisei discubuit, Luc. 7. <Lc. 7, 36>

- Inc. : Conversio et penitentia beate Marie Magdalene data est nobis in exemplum

- Expl. : ... hominis ad Deum. Hec sint dicta de expositione textus evangelii etc, sicut patuit supra.

- Biblio: Madre 1965, p. 240. Hödl \& Koch 1999, N.v.D.185.

24. [Nicolas de Dinkelsbühl], Sermo de santo Jacobo, 1 : fol. $96 \mathrm{r}-99 \mathrm{v}$

- Thema: Nunc accessit ad eum mater filiorum Zebedei cum filiis suis etc. Mt. 20. <Mt. 20, 20>

- Inc. : Iudei Messiam per prophetas promissum estimabant temporaliter regnaturum... 
- Expl. : ... sed humilibus corde, talibus enim paratum est a Patre meo.

- Biblio: Madre 1965, p. 241. Hödl \& Koch 1999, N.v.D.186.

25. [Nicolas de Dinkelsbühl], Sermo de sancto Michaele et de aliis angelis, 1 : fol. 100r-107r

- Inc. : Angeli eorum in celis semper vident faciem Patris mei, qui in celis est. Mt. 18. <Mt. 18, 10>

- Inc. : et legitur in hodierno evangelio. Quamvis non videamus apparitionem angelorum...

- Expl. : ... est laus indeficiens, inmobile decus, regnum solidum et permanens in secula seculorum, amen.

- Biblio: Madre 1965, p. 235. Hödl \& Koch 1999, N.v.D.183.

26. [Nicolas de Dinkelsbühl], Sermo de sancto Michaele et de aliis angelis, 2 : fol. $107 \mathrm{r}-117 \mathrm{v}$

- Thema : In illa hora accesserunt discipuli ad Ihesum dicentes quis putas maior est in regno celorum etc. Mt. 18. $<$ Mt. 18, 1>

- Inc. Hoc evangelium habet tres partes, in quarum prima Dominus loquitur de humilitate...

- Expl. : ... deputatio angeli. Vide de hoc in priori sermone de hac festivitate.

- Biblio: Madre 1965, p. 237. Hödl \& Koch 1999, N.v.D.183.

27. [Nicolas de Dinkelsbühl], Sermo primus de omnibus sanctis : fol. 117v-125r

- Thema : Videns Iesus turbas ascendit in montem et cum sedisset accesserunt ad eum discipuli eius et apperiens os suum docebat eos dicens etc. Mt. quinto. <Mt. 5, 1-2>

- Inc.: Secundum beatum Ambrosium in tractatu super primo psalmo is, qui aliquam sollemnitatem ...

- Expl. : ... merita sunt celestium gaudiorum nos tota mente et tota virtute tendere et feliciter pervenire faciat Ihesus Christus, Dominus noster et redemptor noster, qui cum Patre et Filio et sancto Spiritu vivit et regnat unus Deus in secula seculorum, amen.

- Biblio : Madre 1965, p. 230. Hödl \& Koch 1999, N.v.D.178.

28. [Nicolas de Dinkelsbühl], Sermo secundus de omnibus sanctis : fol. 125r-138r

- Thema : Gloriosa dicta sunt de te, civitas Dei. Ps. 86. <Ps. 86, 3>

- Inc. : Memini me in priore (sic) sermone huius festi aliqua dixisse de hiis que gloriosam, desiderabilem et superiocundam reddunt celestem civitatem...

- Expl. : ... per videre, semper amare et laudare faciat sancta Trinitas et inseparabilis unitas, Pater et filius et Spiritus sanctus unus Deus in eternum benedictus, amen.

- Biblio: Madre 1965, p. 232. Hödl \& Koch 1999, N.v.D.180.

29. [Nicolas de Dinkelsbühl, Sermo de omnibus sanctis, 3] : fol. 138v-144r

- Inc. : Quod sancta mater ecclesia diversorum sanctorum festa instituit, per anni circulum diversis diebus votiva sollemnitate celebranda, hoc ex multis causis fecit et ad fidelium multiplicem profectum. Prima causa est, ut fragiles mortales sanctos immortales venerantes et se eis commendantes mereantur ipsorum precibus adjuvari...

- Expl. : ... delectare posset molestum, ut vult Bernhardus in quadam epistola.

- Biblio: Madre 1965, p. 234. Hödl \& Koch 1999, N.v.D.181.

30. [Magister Alexander Hispanus], Tractatus de quatuor complexionibus (traité médical) : fol. 144v-149v

- Inc. : De complexionibus hominum in mundo viventium et de moribus et statu et vita illorum quia omnis homo in se habet has $4^{\text {or }}$ complexiones. Magister Allexander egregius phisicus et in aliis artibus...

- Expl. : ... qui habet pedes breves et pedicas breves mutabilis est. Et dicta de dispositione hominis sufficiant, magistri Alexandri Yspani.

- Biblio : Thorndike 1955. Thorndike 1958, spécialement p. 404-405

31. [Jacobus de Saraponte], Excerpta ex Aurissa (ars praedicandi) : fol. 150r-154v

- Inc. : Teologya (sic pro Theologia) est scientia pro naturato a naturante ad magnum...

- Expl. : ...non poteris exprimere in latino fac similiter.

- Biblio : Caplan 1934-36, n 173, et suppl. 173. Charland 1936, p. 52.

32. [Jean de Galles], Tractatus de arte predicandi : fol. $155 \mathrm{r}-165 \mathrm{v}$

- Inc. : Ad peticionem cujusdam predilecti satisfaciendum et juniores predicatores...

- Expl. : ... ut pro nobis Filium redemptorem interpellet, quatenus ipso prestante valeamus ad eterna gaudia per venire, amen.

- Biblio : Caplan 1934-36, n 7, et suppl. 7; Charland 1936, p. 55-60; Glorieux 1971, n²34, 1' p. 210; Wenzel 2015, p. 12-13.

33. [Thomas Ebendorfer von Hasselbach], Questio de theoloneo (sic) : fol. 166r-166v

- Inc. : Nota quoddam dubium de theloneo quando juste imponatur, magistri Hasselpach ex sermone 
sancti Mathei. Primo quod sint imposita a superiori potestate..

- Expl. : ... ex quibus satis patet quomodo theolonia (sic) ex multis causis non inmerito habentur suspecta.

- Biblio : cette "nota " est en fait un petit extrait d'un sermon de Thomas Ebendorfer de Hasselbach, en l'occurrence de son premier sermon sur St Matthieu dans sa série Sermones de epistolis de sanctis (Hödl \& Koch 1999, T.E.368)

34. Collecta ex distinctionibus Prepositini cum ejus registro: fol. $167 \mathrm{r}-174 \mathrm{v}$

- Inc. : Annus : quattuor temporibus anni comparantur quattuor tempora mundi...

- Expl. : (fol. 174r) ... Pr. : Scrutator majestatis opprimetur a gloria. Texte suivi d'un index des distinctions au fol. 174r-v.

35. Anonyme, Tractatus de antichristo : fol. 175r-180v

- Inc. : Ascendente Ihesu in naviculam secuti sunt eum discipuli eius. Et ecce motus factus est magnus in mari ita ut navicula operiretur fluctibus. Mt. 8. Navicula scilicet Ecclesiam militantem quam Christus ascendebat cum homo factus est..

- Expl. : ... Deum per essentiam non tamen omnia videt que Deues $(s i c)$ videt eo quod essentiam divinam non comprehendunt (post corr. ex comprehendant).

- Biblio : Lerner 1976.

36. Anonyme, Tractatus de septem gradibus contemplationum : fol. 181r-185r

- Inc. : Ascendam in palmam et apprehendam fructus ejus, Cant. 7. Nota quod septem sunt gradus contemplationis. Primus dicitur ignis, secundus unctio, tertius raptus...

- Expl. : ... palpare ad ignem vel aquam hanc Deo tribuas Spiritui sancto pro instrumento cum quo ipse nos ad eterna gaudia perducat qui cum Patre et Filio vivit et regnat eternaliter benedictus, amen.

- Biblio : Ce traité semble reprendre et amplifier le texte jadis attribué à Bonaventure et édité dans Bonaventure 1868, vol. 12, p. 183-186. Gabriel Théry a défendu une attribution de ce texte à Thomas Gallus, mais celle-ci n'est pas convaincante. Voir Théry 1934 et Lawell 2009.

37. [Johannes Schlitpacher,] Speculum humane salvationis (en vers) : fol. 185v-192v

- Inc. : Autor (sic) libri cui Speculum humane salvationis inposuit nomen in primis duobus capitulis Luciferi et sociorum ejus casum...

- Expl. : ... has etiam binas transeo materias / libri quidam dicti nec habent speculi. Explicit humane- que salutis specula plane / a me fratre Iohanne tui pater ordinis alme / vir benedicte satis exiguo monacho.

- Biblio : Hain 1826-38, Nr. 14929

38. Incipit tractatus de misterio septem artium liberalium prohemium : fol. $193 \mathrm{r}-210 \mathrm{v}$

- Inc. : Apprehendent septem mulieres virum unum, Ysa. 4. Eterna sapientia omni..

- Expl. : ... stultus cui terrena sunt placida sed dicamus orando O sapientia ue ex ore altissimi. Explicit tractatus de misterio 7 artium liberalium. Commentator super primo De celo et III : "In celestibus non sunt plura individua sub una specie".

- Biblio : même texte semble-t-il dans le manuscrit München, Universitätsbibliothek, $4^{\circ}$ COD. MS. 33 (Marianne Reuter, Die Handschriften der Universitätsbibliothek München, vol. 5, Wiesbaden, 2000, p. 50).

39. [Alcuin, De usu Psalmorum] Tractatulus beati Augustini de recommendatione psalterii : fol. $211 \mathrm{r}$ $213 r$

- Inc. : Prophetie spiritus non semper prophetarum mentibus presto est...

- Expl. : ... hec sunt cantica que canit Ecclesia, hec est gloria in qua sancti exultant cum Christo. Amen.

- Biblio: Ce traité contient l'intégralité du texte du De usu Psalmorum d'Alcuin (PL, 101, col. 465-467), avec une dizaine de lignes ajoutées à la fin par rapport à l'édition de la Patrologie Latine.

40. [Caesarius Arelatensis, De sanitate animae, Sermo 50 et Sermo 54], Tractatulus beati Augustini contra sorciarias : fol. $213 \mathrm{v}-216 \mathrm{r}$

- Inc. : Nostis fratres karissimi omnes homines sanitatem corporis querere..

- Expl. : ... et illa supra dicta sacrilegia cum omni horrore fugiat et contempnat. Explicit tractatulus beati Augustini contra sorciarias.

- Ce traité est en fait une compilation de parties de sermons de Césaire d'Arles. Caesarius Arelatensis 1953, sermo 50, parties 1-2, fol. 213v-214r, puis sermo 54, parties 1-5, fol. 214r-216r.

41. [Johannes Teutonicus, Glossae in arborem consanguinitatis (extraits)] : fol. 216v-217r

- Inc.: Gradus est quedam habitudo sive distancia personarum...

- Expl. : ... quia usque ad decimum gradum legalem est consanguinitas, quia ibi fit successio, 35 q. v. ad sedem.

- Biblio : García Y García 1982.

42. [Johannes Teutonicus, Glossae in arborem affinitatis] : fol. $217 \mathrm{r}-217 \mathrm{v}$ 
- Inc. : Affinitas est propinquitas proveniens in nobis ex carnali commixtione parentum nostrorum...

- Expl. : ... ex sponsalibus de futuro sicut aperte innuit finis ejusdem canonis.

- Biblio : García Y García 1982.

43. Arbor consanguinitatis et arbor affinitatis [schémas] : fol. $218 \mathrm{r}-218 \mathrm{v}$

44. De circumcisione : fol. $219 \mathrm{r}$

- Inc. : Ihesus circumciditur octava die secundum legem Moysi hystorice. Allegorice vero Ecclesia militans usurpans...

- Expl. : ... uel parentum si parvule. De hac materia vide in distinctione Super 4 Sententiarum.

45. De epiphania : fol. $219 \mathrm{v}$

- Inc. : Hystoria sancti evangelii patet. Tres enim reges stella duce Herodem pretereuntes...

- Expl. : ... per aliam viam obedientie revertuntur in regionem suam id est in celum.

46. [Johannes Keck] Sermones figuraliter distincti de sanctis per circulum anni (42 sermons) : fol. 220r$252 \mathrm{~V}$

46.a. De s. Andrea : fol. 220r

- Thema : Erat Andreas frater Symonis Petri. Jo. 1. <Jn. $1,40>$

- Inc. : Andreas vero (?) interpretatur virilis, Symon interpretatur obediens, Petrus agnoscens...

- Expl. : ... oratione devota. Jac. 5 : Orate pro invicem ut salvemini, qui converti fecerit...

- Biblio : Le thema et l'incipit correspondent à ceux d'un sermon de Johannes Keck († 1450). Voir Hödl \& Koch 1999, J.K.71.

46.b. De S. Nicolao : fol. 220r-221r

- Thema : Ecce places regi et cuncti servi ejus diligunt te. $1^{a}$ Reg. 18. <1 Rg. 18, 22>

- Inc. : Hystoria de David qui placuerit super alii. Allegoria de S. Nicolao qui dilectus Deo et hominibus...

- Expl. : ... suffragium liberatorum.

- Biblio : Le thema et l'incipit correspondent à ceux d'un sermon de Johannes Keck († 1450). Voir Hödl \& Koch 1999, J.K.88.

46.c. De sanctificatione BMV : fol. $221 \mathrm{r}-22 \mathrm{lv}$

- Thema : Egredietur virga de radice Yesse et flos de radice ejus ascendet, scilicet mediante virga. Ysa. XI. <Is. 11, $1>$

- Inc. : Ambrosius : radix est familia Judeorum...

- Expl. : ... flos est Christus. Cant. 2 : Ego flos campi.

- Biblio : Le thema et l'incipit correspondent à ceux d'un sermon de Johannes Keck († 1450). Voir Hödl \& Koch 1999, J.K.89.

46.d. De S. Thoma : fol. $221 \mathrm{v}-222 \mathrm{r}$
- Thema : Dominus meus et Deus meus. Jo. 20. <Jn. 20, $>$

- Inc. : Gregorius in omelia : palpavit autem et exclamavit Dominus meus et Deus meus et subdit : plus enim nobis infidelitas Thome quam fides credentium discipulorum profuit...

- Expl. : ... bonitate perfecta omnia circumspiciens et continens et se implens et excedens omnia.

- Biblio : Le thema et l'incipit correspondent à ceux d'un sermon de Johannes Keck († 1450). Voir Hödl \& Koch 1999, J.K.90.

46.e. De s. Stephano : fol. 222r-222v

- Thema: Stephanus autem plenus gratia et fortitudine. Act. $6<$ Act. $6,8>$

- Inc. : Tria sunt homini necessaria scilicet gratia vite meritorie...

- Expl. : ... lapidea. Ps. : Posuisti in capite ejus coronam de lapide pretioso, eternitas, stabilitas.

- Biblio : Le thema et l'incipit correspondent à ceux d'un sermon de Johannes Keck († 1450). Voir Hödl \& Koch 1999, J.K.91.

46.f. De s. Johanne Evangelista : fol. 222v-223r

- Thema: Amice, ascende superius. Luc. 14. <Lc. 14, $10>$

- Inc. : Hic tria innuuntur, scilicet suavis affectus in dilectione...

- Expl. : ... virginitati cautela adhibenda est in mente, sermone, opere.

- Biblio : Le thema et l'incipit correspondent à ceux d'un sermon de Johannes Keck († 1450). Voir Hödl \& Koch 1999, J.K.92.

46.g. De Innocentibus : fol. $223 \mathrm{r}-223 \mathrm{v}$

- Thema : Pueri mei mecum sunt in cubili. Luc. XI. <Lc. $11,7>$

- Inc. : Hic tria innuuntur ipsis innocentibus applicanda, que etiam habentur exempla. Puritas corporis...

- Expl. : ... opere sufficiens est non autem contra opus.

- Biblio : Le thema et l'incipit correspondent à ceux d'un sermon de Johannes Keck († 1450). Voir Hödl \& Koch 1999, J.K.93.

46.h. De s. Agnete : fol. 223v-224r

- Thema : Virgo cogitet que Domini sunt ut sit sancta corpore et spiritu. 1 Cor. 7. < 1 Cor. 7, 34>

- Inc. : Beata Agna elegit agnum Dei qui tollit peccatum mundi. Virginitas corporis et mentis...

- Expl. : Jo. 10 : Ingredietur et egredietur et pascua inveniet.

- Biblio : Le thema et l'incipit correspondent à ceux d'un sermon de Johannes Keck († 1450). Voir Hödl \& Koch 1999, J.K.100. 
46.i. De conversione Sancti Pauli : fol. $224 \mathrm{r}-224 \mathrm{v}$

- Thema : Vas admirabile, opus excelsi, in meridiano exuret terram. Eccli. 43. <Eccli. 43,2>

- Inc. : In hys verbis sanctus Paulus commendatur quantum ad tria, scilicet quantum ad esse...

- Expl. : ... correctio culpe in caritate. In quo corrigit adolescentior.

- Biblio : Le thema et l'incipit correspondent à ceux d'un sermon de Johannes Keck († 1450). Voir Hödl \& Koch 1999, J.K.101.

46.j. In festo candelarum : fol. 225r-225v

- Thema : Alia est claritas solis, alia claritas lune, alia claritas stellarum. 1 Cor. 15. <1 Cor. 15, 41>

- Inc. : Gn. 1 fecit Deus duo luminaria magna et stellas. Sergius papa instituit...

- Expl. : ... gloria patrie quia premiator. Ps. : Gloria virtutis eorum tu es.

- Biblio : Le thema et l'incipit correspondent à ceux d'un sermon de Johannes Keck († 1450). Voir Hödl \& Koch 1999, J.K.102.

46.k. In katedra Petri : fol. 225v-227r

- Thema : Tu es Petrus. Mt. 16. <Mt. 16, >

- Inc. Sanctus Petrus notatur in trina...

- Expl. : ... satisfactione purgantur a salvatore recipiuntur.

46.l. De s. Mathia Apostolo : fol. 227r-227v

- Thema : Pro urtica crescet (corr. ex. crevit) mirtus. Ysa. 55. <Is 55,13>

- Inc. : Ps : Fiant dies eius pauci, et episcopatum ejus accipiat...

- Expl. : ... martirio roboravit, quia lapidatus securi percussus.

- Biblio : Le thema et l'incipit correspondent à ceux d'un sermon de Johannes Keck († 1450). Voir Hödl \& Koch 1999, J.K.107.

46.m. De s. Gregorio : fol. 227v-228r

- Thema : Vigil et sanctus de celo descendit. Dan. 4. <Dn. $4,10>$

- Inc. : Mt. 24 : Vigilate, quia nescitis qua hora Dominus vester venturus sit. Gregorius nomen grecum est et interpretatur vigil vel vigilans...

- Expl. : ... reducit. Ps. : Erravi sicut ovis que etc. Petr. : Eratis sicut oves errantes.

46.n. In annunciatione Beate Marie Virginis] : fol. 228r$229 r$

- Thema: Veniat dilectus meus in ortum sum. Cant. 5. $<$ Ct. $5,1>$

- Inc. : Veni Domine, et noli tardare, quia prophetavit Ysa. 7 : Ecce virgo concipiet etc. Ortum commendat : avium cantus suavitas...
- Expl. : ... in virore permansit. Jo. 19 : Stabat juxta crucem id est mater ejus

- Biblio : Le thema et l'incipit correspondent à ceux d'un sermon de Johannes Keck († 1450). Voir Hödl \& Koch 1999, J.K.109.

46.o. De armis Christi : fol. 229r-229v

- Thema : Apprehende arma et scutum et exurge in adjutorium michi. Ps. 34. <Ps. 34, 2>

- Inc. : Ecce rex noster venit Dominus terre et aufert jugum capitis (sic pour captivitatis) nostre...

- Expl. : ... vinum mirratum cum felle mixtum, et funes.

46.p. De S. Gregorio : fol. 230r-230v

- Thema : Labora sicut bonus miles Christi. 2 Tim. $2^{\circ}<2$ Tim. 2,3>

- Inc.: Job 7: Militia est vita hominis super terram. Apostolus : Nemo coronabitur nisi qui legitime certaverit. Miles sit fidelis : labora...

- Expl. : ... non ingreditur ad eos. Ex legenda sancti Jeronimi applica materiam predictam.

- Biblio : Le thema et l'incipit correspondent à ceux d'un sermon de Johannes Keck († 1450). Voir Hödl \& Koch 1999, J.K.117.

46.q. De S. Marco : fol. 230v-23lr

- Thema: In medio sedis et in circuitu sedis quatuor animalia plena oculis ante et retro. Et animal primum simile leoni, et secundum animal simile aquile volanti. Apock. $4^{\circ}$. <Apc. 6-7>

- Inc. : Per ista $4^{\text {or }}$ animalia quatuor evangeliste figurantur, quorum quilibet...

- Expl. : ... que sole et fonte renovatur. Eze. 17.

- Biblio : Le thema et l'incipit correspondent à ceux d'un sermon de Johannes Keck († 1450). Voir Hödl \& Koch 1999, J.K.118.

46.r. De S. Philippo et Jacobo : fol. 231 r-23lv

- Thema : Gaudete, quia nomina vestra scripta sunt in celis. Luc. 10. <Lc. 10, 20>

- Inc. : Sed impy, ut dicit Ps. vocaverunt nomina sua in terris suis...

- Expl. : ... 3, contemplationem : lucerna pedibus meis verbum tuum.

- Biblio : Le thema et l'incipit correspondent à ceux d'un sermon de Johannes Keck († 1450). Voir Hödl \& Koch 1999, J.K.122.

46.s. De inventione S. Crucis : fol. 231v-232v

- Thema : Invenit Moyses lignum in deserto quod cum mississet in aquas Marath dulcorate sunt, Exo. 15. <Ex. $15,25>$

- Inc. : Gn 2 Produxitque Dominus Deus de humo omne lignum...

- Expl. : ... penarum eternitas. 
- Biblio : Le thema et l'incipit correspondent à ceux d'un sermon de Johannes Keck († 1450). Voir Hödl \& Koch 1999, J.K.123.

46.t. De S. Johanne Baptista : fol. 232v-233v

- Thema : Johannes est nomen ejus. Luc. 1 <Lc. 1, 63>

- Inc. : Res cognoscitur ex nomine. Exo. 32 : Novi te ex nomine...

- Expl. : Johannes processit nascendo, moriendo, ad limbum descendendo.

- Biblio : Le thema et l'incipit correspondent à ceux d'un sermon de Johannes Keck († 1450). Voir Hödl \& Koch 1999, J.K.7.

46.u. De S. Apostolis Petro et Paulo : fol. 234r-235r

- Thema : Saul et Jonathas amabiles valde et decori in vita sua, in morte quoque non sunt divisi. 2 Reg. 1. <2 Rg. 1, 23>

- Inc. : Apostoli commendantur ex proprietate nominis...

- Expl. : ... felicitatem. Jo. 14 : Iterum veniam, et assumam vos ad me ipsum, et ubi ego sum, ibi et vos sitis.

- Biblio : Le thema et l'incipit correspondent à ceux d'un sermon de Johannes Keck († 1450). Voir Hödl \& Koch 1999, J.K.8.

46.v. De visitatione B. Virginis : fol. $235 \mathrm{r}-235 \mathrm{v}$

- Thema: Que est ista que ascendit de deserto delicys affluens, innixa super dilectum suum? Cant. ult. <Ct. 8, 5>

- Inc. : Que est ista, id est quanta laude digna est ista virgo, que ascendit de virginitate in virginitatem...

- Expl. : ... vox angeli Salomonem homini nunciavit, Salomon fertur inter mulieres, contra maledictionem Eve.

- Biblio : Le thema et l'incipit correspondent à ceux d'un sermon de Johannes Keck († 1450). Voir Hödl \& Koch 1999, J.K.9.

46.w. De S. Margaretha : fol. 235v-236r

- Thema: Inventa una preciosa margarita abiit, et vendidit omnia que habuit, et emit eam. Mt. 13. <Mt. 13, 46>

- Inc. : Per margaritam istam significatur humana natura sive militans Ecclesia, ad quam recuperandam...

- Expl. : ... in forma draconis apparuit Apock. 12, draco qui projectus

- Biblio : Le thema et l'incipit correspondent à ceux d'un sermon de Johannes Keck († 1450). Voir Hödl \& Koch 1999, J.K.10. Le thema et le premier paragraphe sont identiques à ceux d'un sermon attribué à Siboton (Sigibottus), dominicain viennois actif à la fin du XIII siècle (Schneyer 1969-90, vol. 5, p. 420-421, Siboto $n^{\circ} 259$ ), en tout cas tel qu'il est transmis par le ms. Assisi, Sacro convento, 432, fol. 72vb-73ra. Après le premier paragraphe, les sermons divergent: dans le manuscrit d'Assise le développement se poursuit, tandis que dans notre manuscrit suit directement une distinction schématisée en dix parties. V. également : Schneyer 1967, p. $204, \mathrm{n}^{\circ} 157$.

46.x. De Magdalena : fol. 236r-237r

- Thema : Ut cognovit quod Jhesus accubuisset in domo pharisey attulit alabastrum unguenti et stans retro secus pedes Domini Jhesu lacrimis cepit rigare pedes ejus et capillis suis tergebat. Luc. 7. <Lc. 7, 37-38>

- Inc. : In hys verbis duplex convivium innuitur Domino preparatum...

- Expl. : ... sed propter ipsum hominem. Luc. 19 : Quare non dedisti pecuniam meam ad mensam ut ego veniens cum usuris etc.

- Biblio : Le thema et l'incipit correspondent à ceux d'un sermon de Martin de Troppau (Schneyer 1969-90, vol. 4, p. 142, n²48), mais l'explicit diffère.

46.y. De S. Jacobo et Philippo : fol. 237r-237v

- Thema : Dic ut sedeant hy duo fily mei unus ad dexteram tuam et unus ad sinistram in regno tuo. Mt. 20. <Mt. 20, 21>

- Inc. : Et fily Zebedei, Zebedeus interpretatur 'donatus' vel 'dotatus'...

- Expl. : ... loci altitudinem. Ps. 90 : Altissimum posuisti refugium tuum, non...

- Biblio : Le thema et l'incipit correspondent à ceux d'un sermon de Johannes Keck († 1450). Voir Hödl \& Koch 1999, J.K.21.

46.z. Ad vinculam Petri : fol. 238r-238v

- Thema : Misit Herodes Petrum in carcerem. Act. 12. $<$ cf. Act. 12, 4>

- Inc. : Beatus Petrus Judeis accusantibus...

- Expl. : ... recondite sunt ab Eudoxia regina, Augustinus cum Anthonio.

- Biblio: Le thema et le premier paragraphe sont identiques à ceux d'un sermon anonyme contenu dans le manuscrit Troyes, Bibliothèque Municipale, 1251, fol. 208ra-209vb. Le texte diffère ensuite, et la première distinction de notre sermon semble correspondre à l'incipit d'un sermon sur le même thema de Johannes Keck († 1450). Voir Hödl \& Koch 1999, J.K.22.

46.aa. De S. Laurentio : fol. 238v-239r

- Thema : Probasti cor meum et visitasti nocte. Ps. 16. $<$ Ps. 16, 3>

- Inc. : Hic duo innuuntur scilicet beati Laurenty martirium... 
- Expl. : Ys. 23 : Ignis hostes tuos devoret, sive Mt. 25 : Discedite a me.

- Biblio : Le thema et l'incipit correspondent à ceux d'un sermon de Johannes Keck († 1450). Voir Hödl \& Koch 1999, J.K.29.

46.ab. De assumptione Beate Virginis : fol. $239 \mathrm{v}-240 \mathrm{r}$

- Thema : Maria optimam partem elegit que non aufferetur ab ea. Luc. $10<$ Lc. 10, 42>

- Inc. : David bonam partem elegit inter famem gladium...

- Expl. : ... filius tuus. Cant. ult. : Que est ista que ascendit de deserto deliciis affluens?

46.ac. De S. Bartholomeo : fol. 240r-240v

- Thema : Percusserunt me, vulnaverunt me custodes murorum. Cant. 5. <Ct. 5, 7>

- Inc. : Hec verba possunt exponi de peccante, de penitente, de sancto Bartholomeo paciente...

- Expl. : ... virtutes predictas habuit sanctus Bartholomeus ut in legenda sua.

- Biblio : Le thema et l'incipit correspondent à ceux d'un sermon de Johannes Keck († 1450). Voir Hödl \& Koch 1999, J.K.38.

46.ad. De decollatione S. Johannis : fol. 240v-24lr

- Inc. : Sancti Johannis argumentatio...

- Expl. : .. beatus in utero, mundo, celo.

46.ae. De Nativitate Beate Virginis : fol. 24lr-24lv

- Thema : Plantaverat autem Dominus Deus paradisum voluptatis a principio, in quo posuit hominem. Gn. 2 . $<$ Gn. 2, 8>

- Inc. : In primo paradiso Adam peccavit...

- Expl. : ... per hunc in invisibilium amorem rapiamur.

- Biblio : Le thema et l'incipit correspondent à ceux d'un sermon de Johannes Keck († 1450). Voir Hödl \& Koch 1999, J.K.39.

46.af. De exaltatione S. Crucis : fol. 24lv-243r

- Thema : Ego Dominus exaltavi lignum humile. Ezech. $17<$ Ez. 17, 24>

- Inc. : Dictum est supra in sermone de inventione sancte crucis de duplici ligno paradisi...

- Expl. : 5, Cant. 3, Tenui eum nec dimittam, Prover. 3, Lignum vite hys qui apprehenderint eam.

46.ag. De S. Mattheo Evangelista : fol. 243r-244v

- Thema : Tertium animal habens faciem quasi hominis. Apock. 4. <Apc. 4, 7>

- Inc. : Eze. et 10 in visione spirituali 4or viderunt animalia que secundum doctores Ecclesie significant 4or evangelistas, inter que animalia in Apock. est tertium animal habens faciem quasi hominis, per quod interpretatur sanctus Matheus. Per faciem secundum Gregorium significatur notitia...
- Expl. : ... occisus est in mundo sed jam ut homo cum Christo Deo et homine gloriose vivit in celo.

- Biblio : Le thema et l'incipit correspondent à ceux d'un sermon de Johannes Keck († 1450). Voir Hödl \& Koch 1999, J.K.47.

46.ah. De S. Michahele : fol. 244v-246v

- Thema : Angeli eorum in celis semper vident afciem Patris mei qui in celis est. Mt. 18. <Mt. 18, 10>

- Inc. : Ierarchia est rerum sacrarum et rationabilium ordinata...

- Expl. : ... in statu vite contemplative, in statu glorie baiulando, associando, collaudando.

- Biblio : Le thema et l'incipit correspondent à ceux d'un sermon de Johannes Keck († 1450). Voir Hödl \& Koch 1999, J.K.48.

46.ai. De S. Luca : fol. 246v-247v

- Thema : Misit illos binos ante faciem suam. Luc. 10. $<$ Lc. 10, 1>

- Inc. : 12 apostoli sunt forma prelatorum, 72 discipuli sacerdotum...

- Expl. : ... transfundens de apostolis Symone et Juda.

46.aj. De apostolis Symone et Juda : fol. 247v-248r

- Thema : Ecce Symon frater vester, scio quod vir consily est, ipsum audite semper, et ipse erit vobis pater. Et Judas Machabeus (id est protegens ajouté en interligne d'une autre main), fortis viribus, id est juventute sua, sit vobis princeps militie, et ipse aget bellum populi. 1 Macchab. $2<1$ Mcc. 2, 65-66>

- Inc. : Hec verba dixit Mathathias filys suis. Symon interpretatur obediens...

- Expl. : ... Ps. : Confitebor tibi quia terribiliter magnificatus es.

- Biblio : Le thema et l'incipit correspondent à ceux d'un sermon de Johannes Keck († 1450). Voir Hödl \& Koch 1999, J.K.61.

46.ak. De omnibus sanctis : fol. 248r-248v

- Thema : Congregate illi sanctos ejus. Ps. 49. <Ps. 49, 5>

- Inc. : Congregate, id est ad memoriam simul revocate illi scilicet Deo deorum...

- Expl. : ... 6 : Deuter. 28, Venientque super te universe benedictiones iste, et apprehendent te, si tamen precepta ejus audieris.

- Biblio : Le thema et l'incipit correspondent à ceux d'un sermon de Johannes Keck († 1450). Voir Hödl \& Koch 1999, J.K.62.

46.al. Benedictiones Dei, orationes Ecclesie de animabus : fol. 248v-249r

- Thema : In omnibus operibus tuis memorare novissima tua et in eternum non peccabis. Eccli. 7. <Eccli. $7,40>$ 
- Inc. : Dicitur enim la Jo. 2: Omne quod in mundo est ...

- Expl. : ... perpetua. Ys. ult. : vermis eorum non morietur.

- Biblio : Le thema et l'incipit correspondent à ceux d'un sermon de Johannes Keck († 1450). Voir Hödl \& Koch 1999, J.K.63.

46.am. De S. Martino : fol. 249r-250r

- Thema : Enoch placuit Deo et translatus est in paradisum. Eccli. 44. <Eccli. 44, 16>

- Inc.: Enoch interpretatur 'cum Deo ambulans'. Ps. : Dissipavit Dominus ossa eorum...

- Expl. : .. Enoch translatus est in paradisum terrestrem, Martinus in paradisum celestem.

46.an. De S. Martino fol. 250r-250v

- Thema : Enoch placuit Deo et translatus est in paradisum, ut supra. <Eccli. 44, 16>

- Inc. : Hic tria innuuntur de Sancto Martino : bene dispositus in vita...

- Expl. : ... castitas in refrenando cor sensus carnem.

- Biblio : Le thema et l'incipit correspondent à ceux d'un sermon de Johannes Keck († 1450). Voir Hödl \& Koch 1999, J.K.66.

46.ao. De S. Elizabeth : fol. 250v-25 lr

- Thema : Vidit autem et quandam viduam pauperculam mittentem era minuta duo scilicet in gazophilacium. Luc. 21. <Lc. 21, 2>

- Inc.: Prover. ult.: Mulierem fortem quis inveniet procul, $<$ Pr. 31, 10> id est virtuosam...

- Expl. : ... nec perpendit quantum offeramus in ejus sacrificio sed ex quanto.

- Biblio : Le thema et l'incipit correspondent à ceux d'un sermon de Johannes Keck († 1450). Voir Hödl \& Koch 1999, J.K.69. Cf. également sermon d'Aldobrandinus de Cavalcantibus pour la même occasion (Schneyer 1969-90, vol. 1, p. 210 , $\left.n^{\circ} 821\right)$.

46.ap. De S. Katherina : fol. 251r-252v

- Thema : Omnium Dominus dilexit illam. Sap. 8. <Sap. $8,3>$

- Inc. : In Ethicarum, omnis congregatio fit secundum similitudinem...

- Expl. : ... beata propter auream et tripliciter aureolam.

- Biblio : Le thema et l'incipit correspondent à ceux d'un sermon de Johannes Keck († 1450). Voir Hödl \& Koch 1999, J.K.70.

47. De Chorea : fol. 252v-253r

- Thema : In circuitu impy ambulant. Ps. XI. <Ps. 11, 9>

- Inc. : Item chorea est circulus cujus centrum est dyabolus...
- Expl. : ... cantica vel musica de honesta re non turpi.

48. De reliquiis sanctorum : fol. $253 \mathrm{r}-253 \mathrm{v}$

- Thema : Reliquie cogitationis diem festum agent tibi. Ps. 75. <Ps. 75, 11>

- Inc. : Reliquie sanctorum sunt reliquie cogitationis id est in cogitatione retinende...

- Expl. : ... Ys. 58 : Ossa tua liberabit scilicet ab incineratione in resurrectione generali et glorificabit claritate perpetua.

49. Prothemata : fol. $253 v-254 \mathrm{r}$

- Inc. : Beati qui audiunt verbum Domini et custodiunt illud. Luc. XI <Lc. 11, 28>. Eph. 5, Apostolus: Unus est sermo Dei et efficax <Hbr. 4, 12>. Est enim multiplicis virtutis...

- Expl. : ... in memoria custodiendum. Luc. XI : Beati qui audiunt verbum Dei. In carta scribendum, Eccle. ul. : scripsit sermones rectissimos.

50. [Notes] : fol. 254r-254v

- Inc. : Predicabile est quod aptum natum est predicari de pluribus...

- Expl. : 10 --- habitus --- claidung --- Phil. : Et habitu inventus ut homo.

- Biblio: Ces notes munies de gloses en allemand sont tirées ou fortement inspirées d'extraits des Summule logicales de Pierre d'Espagne. V. Petrus Hispanus 1972, p. 17.

51. Sermo de sorte : fol. 254v-256r (255r)

- Thema: Dixi Deus meus es tu, in manibus tuis sortes mee. Ps. $30<$ Ps. 30, 15-16>

- Inc. : In potestate Dei sunt sortes hominis multiplices...

- Expl. : ... Ps. : In nomine tuo magnificabimur. Mt. 4 : Non est aliud nomen sub celo.

- Pas de feuillet numéroté 255 dans la foliotation médiévale, par erreur.

52. In dedicatione : fol. 256r-256v (255r-255v)

- Thema : Vere Dominus est in loco isto, Gn. 28. <Gn. 28, 16>

- Inc. : Domino debetur reverentia...

- Expl. : ... Augustinus : In domo Dei nemo aliquid agat nisi ad quod factum est. Prover. 9 : Sapientia edificat sibi domum, excidit columpnas septem. Gen. 28 Jacob erexit lapidem in titulum, fundens oleum desuper.

53. Idem, alius sermo : fol. 256v-257r (255v-256r)

- Thema : Non est arbor bona que facit fructus malos neque arbor mala faciens fructum bonum, Luc. 6. <Lc. 6, 43>

- Inc.: Gregorius quotienscumque sensibilium rerum... 
- Expl. : ... si placet quodlibet membrum seorsum subdividendo.

54. Item, alius sermo : fol. 257r (256r)

- Thema: Sicut malus inter ligna silvarum, sic dilectus meus inter filios. Cant. $2^{\circ} .<$ Ct. 2, 3>

- Inc. : De qua arbore dicitur libro de plantis...

- Expl. : ... perfectus vendat omnia.

55. Item, alius sermo : fol. 257r-257v (256r-256v)

- Thema : Mundate domum Domini mei. 2 Paralip. 3.

- Inc. : Crisostomus super $1^{\circ}$ Marci : penitentiam agite, penitentia cor mundat...

- Expl. : ... item ibi dic quot mala homo incurrit per peccatum et per quot sanatur, ut habes in compendio.

56. [Jacques de Voragine], De dedicatione ecclesie (extrait de la Legenda aurea) : fol. 257v-264r (256v263r)

- Inc. : Dedicatio ecclesie inter alias festivitates sollempniter ab Ecclesia celebratur. Et quoniam duplex est ecclesia sive templum scilicet materiale et spirituale, ideo de hujus templi dupplici dedicatione hic breviter agendum...

- Expl. : ... in quo Christus habitat per gratiam ut tandem in eo habitare dignetur per gloriam quod ipse nobis prestare dignetur qui vivit et regnat Deus per secula seculorum amen.

- Biblio : Iacopo da Varazze 2007, p. 1440-1459.

57. Nota de prima dedicatione: fol. 264r-264v (263r263v)

- Inc. : Nota hic de prima dedicatione. Salomon enim edificavit Domino templum de marmore candida...

- Expl. : ... noli ergo tardus esse ad dedicationem et gaudium obtinebis.

- Biblio : ce texte pourrait correspondre au sermon référencé dans Schneyer 1969-90, vol. 9, p. 629, nr. 81, mais amputé de son théma et de sa phrase introductive. L'absence d'explicit dans le Repertorium ne nous permet pas d'en être certains sans vérifications ultérieures.

58. Collatio de novo sacerdote: fol. 265r-268r (264r267r)

- Thema : Memento mei, cum bene tibi fuerit, Gen. 40. $<$ Gn. 40, 14>

- Inc. : Venerabiles patres ceterique domini honorandi, hec verba ut themata ponit verbis..

- Expl. : ... revelandum que est benedictus Deus in secula seculorum amen.

59. Notule en forme schématisée sur les paroles de St Grégoire : fol. 268r (267r)

- Inc. : Dicit Gregorius de potestate clavium ligandi...

- Expl. : ... judex fiat aliena.
60. De dedicatione : fol. 268r-274r (267r-273r)

- Thema : Nescitis quia templum Dei estis vos et Spiritus Dei habitat in vobis? Si quis autem templum Dei violaverit, disperdet illum Deus. Templum enim Dei sanctum est, quod estis vos. Prima ad Cor. tertio. <1Cor. 3, 16>

- Inc. : Augustinus : quotienscumque templi vel altaris festivitate...

- Expl. : ... dignitatem et valorem animarum.

61. [Item, de dedicatione] : fol. 274r-276v (273r-275v)

- Inc. : Edificate domum et acceptabilis mihi erit et glorificabo, dicit Dominus, Aggei primo <Agg. 1, 8>

- Inc. : propter quod sciendum quod Deus qui habet in femore suo..

- Expl. : ... debet justus terreri in gratiarum actionem ex humilitate.

- fol. 277r-277v (dans la foliotation médiévale) blanc. Ce folio a été retiré après la réalisation de la reproduction photographique sur laquelle nous avons travaillé pour cette description, et est aujourd'hui manquant.

62. Collatio de sacerdotibus : fol. 278r-279r (276r-277r)

- Thema : Labia sacerdotis custodiunt scientiam et legem requirunt ex ore ejus. Malach. 3. $<$ Mal. 2, 7>

- Inc. : Inter alias dignitates maxima est illa quam Deus sacerdotibus tradidit...

- Expl. : ... super quem anima transire potest ad Deum et evadere de fluvio infernali.

63. De prelatis : fol. 279r (277r)

- Thema : Ego sum pastor bonus, Jo. 10. <Jn. 10, 11 vel 14>

- Inc. : Ibi innuitur benevolentia dilectionis, sapientia conditionis, diligentia subventionis...

- Expl. : ... et mercenarii et ovium invenies alibi circa evvangelium Ego pastor bonus.

64. De exaltatione sancte crucis : fol. 279r-281r (277r279r)

- Thema : Quasi cedrus exalta (sic) sum in Libano et quasi cipressus in monte Syon, quasi palma exaltata sum in Cades, et quasi plantatio rose in Jericho, quasi oliva speciosa in campis et quasi platanus exaltata sum juxta aquas. Eccli. 24. <Eccli. 24, 17-19>

- Inc. : Consuetudo magnorum dominorum comitum et populorum sicut antiquitus...

- Expl. : ... et invidie calefacit caritate et divina gratia. Bene ergo dicitur quasi platanus.

65. De exaltatione crucis, alius sermo : fol. $281 \mathrm{r}-282 \mathrm{v}$ (279r-280v)

- Thema : Mihi autem absit gloriari nisi in cruce Domini nostri Ihesu Christi. Gal. 6. <Gal. 6, 14>

- Inc. : De cruce tria principalia sunt notanda, scilicet ejus notitia, causa et efficacia... 
- Expl. : ... cipressus famam bone operationis, palma fructum justitie, oliva lenitatem misericordie.

- Biblio : Cf. Augsburg, Cod. II. 1. 4²0, f. 130-131v (Hilg 2007, p. 229).

66. De sacerdotibus fol. $282 \mathrm{v}-284 \mathrm{r}$ (280v-282r)

- Thema : Benedicite, sacerdotes Domini, Domino. Dan. 3. $<$ Dn. 3, 84>

- Inc. : Benedicere tunc dicuntur sacerdotes Domini Domino quando officium....

- Expl. : ... subicere oporteat judicium condempnationis. Juxta illud I Cor. XI : si nos ipsos dijudicaremus non utique judicaremur.

67. Collatio in nundinis : fol. 284r-285r (282r-285r)

- Thema : Suadeo tibi emere a me aurum ignitum probatum ut locuples fias et vestimentis albis induaris et non appareat confusio nuditatis tue, Apok. 3. <Apc. 3, 18>

- Inc. : Hec verba per testem fidelem qui est principium creature Dei...

- Expl. : ... caritas operit multitudinem peccatorum. Ps. : Beati quorum remisse sunt iniquitates et quorum tecta sunt peccata.

68. [ad sacerdotes] : fol. 285r-286r (283r-284r)

- Thema: Quis putas est fidelis servus et prudens quem constituat dominus super familiam suam ut det illis cibum in tempore? Mt. 24, <Mt. 24, 45> Luc. 12. <Lc. $12,42>$

- Inc. : Hec verba dicuntur principaliter de servo ecclesiastico scilicet de quolibet sacerdote...

- Expl. : ... datur in eternitate, de quo dicitur Thob. 12: Ego cibo invisibili et potu qui ab hominibus videri non potest, utor.

69. Sermo ad populum : fol. $286 \mathrm{v}-287 \mathrm{v}(284 \mathrm{v}-285 \mathrm{v})$

- Thema : Quis putas est fidelis servus et prudens, Mt. 24, Luc. 12.

- Inc. : Ex litera patet distinctio quod quidam infideles servi sunt et imprudentes, quidam vero fideles et prudentes...

- Expl. : ... de servis triumphantis Ecclesie dicitur 3 Reg. 10 : Beati servi qui stant coram te semper et audiant sapientiam tuam.

70. Sermo ad clerum in anniversario Cesaris : fol. 288r$291 \mathrm{l}(286 \mathrm{r}-289 \mathrm{r})$

- Thema : Sacerdotes qui accedunt ad Dominum sanctificentur ne percutiam eos. Exo. 19. <Ex. 19, 22>

- Inc. : Venerabiles patres ceterique domini honorandi vestra novit caritas. Item legitur Numer. 16 quod Aaron obtulit thimiama...

- Expl. : ... archam Domini nisi a sacerdotibus. Suit une note additionnelle sur les "sacerdotes", dont une distinction les comparant aux chœurs angéliques.
71. Collatio in fraternitate : fol. $291 \mathrm{v}-295 \mathrm{r}(289 \mathrm{v}-293 \mathrm{r})$

- Thema : Ecce quam bonum et quam jocundum habitare fratres in unum. Ps. 132. <Ps. 132, 1>

- Inc.: Venerabiles patres ceterique Domini honorandi vestra novit caritas, quia Luc. 10 dicit veritas, porro unum est necessarium....

- Expl. : ... sit nobiscum Dei pax et gratia ut tandem habitemus cum Domino et confratre nostro Jhesu Christo in gloria qui est Deus benedictus in secula seculorum, amen.

72. Sermo ad cives : fol. 295v-297v (293v-295v)

- Thema : Murus civitatis habens fundamenta duodecim et in ipsis nomina duodecim apostolorum et agni, Apoc. 21. <Apc. 21, 14>

- Inc. : Civitas pollitica ut dicitur in libro Yconomicorum est domorum pluralitas...

- Expl. : ... Baruch 3 : stelle autem dederunt lumen in custodys suis.

73. Sermo de Trinitate : fol. 298r-299v (296r-297v)

- Thema : Sanctus sanctus sanctus Dominus Deus omnipotens. Apock. 4. <Apc. 4, 8>

- Inc. : Concordat Ys. 6 quantum ad dictum, sed quantum ad dicentes Johannes insinuat quatuor animalia...

- Expl. : ... in celis glorificabitur argentum castitatis aurum caritatis.

74. Sermo communis : fol. 300r-30lr (298r-299r)

- Thema : Justum deduxit Dominus per vias rectas. Sap. 10. <Sap. 10, 10>

- Inc. : In exilio hujus mundi multi sunt devia...

- Expl. : ... alie vie hominis, de quibus in Ps. : Inquinate sunt vie illius in omni tempore.

75. Divisio symbolis Athanasii : fol. 301v-304r (299v302r)

- Inc. : Quicumque vult salvus esse. Illud symbolum traditum est ab egregio doctore Athanasio Alexandrino episcopo ut Ecclesia Dei muniretur expositionibus articulorum fidei veris et approbatis...

- Expl. : ... purificatur enim anima per fidem sed firmatur per caritatem. Act. 15 : Et fide purificans corda eorum. Gal. 6: Et fides que per dilectionem operatur. Can. 8 : Fortis est ut mors dilectio.

76. Expositio ejusdem symboli : fol. 304r-306v (302r$304 \mathrm{v})$

- Inc. : Quicumque vult salvus esse. Et fides est credulitas rerum ad Deum pertinentium que non videntur. Quicumque id est unusquisque qui vult id est cupit...

- Expl. : ... illius purgatorii qui est salutaris, hec fides katholica, illam clausulam sepius repetit ut ipsam fidem necessariam in cordibus fidelium artius incalcaret. 
- Biblio : un texte similaire pourrait être contenu dans le manuscrit Milano, Ambrosiana, M. 79. Sup. Cf. Swainson 1875, p. 423-425.

77. [Texte sur le Credo] : fol. 307r-309r (305r-307r)

- Inc. : Notandum quod secundum Richardum de Sancto Victore articulus fidei ita describitur : est indivisibilis veritas ...

\section{Bibliographie}

\section{Ouvrages à caractère de source}

Bonaventure $1868=$ Bonaventurae Opera Omnia, éd. A.C. Peltier, Paris, 1868.

Caesarius Arelatensis $1953=$ Caesarius Arelatensis, Sermones, éd. G. Morin, Turnhout, 1953 (CCSL, 103).

Iacopo da Varazze 2005 = Iacopo da Varazze, Sermones Quadragesimales, ed. Giovanni Paolo Maggioni, Firenze, 2005.

Iacopo da Varazze 2007 = Iacopo da Varazze, Legenda aurea - con le miniature del codice Ambrosiana C 240 inf., éd. critique G.P Maggioni, trad. italienne coordonnée par F. Stella, Florence-Milan, 2007.

Jean Gerson 1971 = Jean Gerson, Euvres complètes, vol. VIII (L'œuvre spirituelle et pastorale [399-422]), éd. P. Glorieux, Paris, 1971.

Petrus Hispanus 1972 = Peter of Spain (Petrus Hispanus Portugalensis), Tractatus called afterwards Summule logicales, éd. Lambertus Marie de Rijk, Assen, 1972.

Prévostin de Crémone 1969 = Praepositini Cremonensis Tractatus de officiis, ed. James A. Corbett, Notre DameLondon, 1969.

Walz 1955 = A. M. Walz, Des Aage von Dänemark Rotulus Pugillaris, dans Classica et mediaevalia, 16, 1955, p. 135-194.

Werminghoff 1903= A. Werminghoff, Ein Tractatus de coronatione imperatoris aus dem vierzehnten Jahrhundert, dans Zeitschrift der Savigny-Stiftung für Rechtsgeschichte / Germanistische Abteilung, 24-1, 1903, p. 380-390.

\section{Études secondaires}

Bartoš 1948 = F.M. Bartoš, Literární činnost M. Jana Husi, Praha, 1948.

Bériou $1998=\mathrm{N}$. Bériou, L'avènement des maîtres de la Parole. La prédication à Paris au XIIIe siècle, Paris, 1998, 2 vol. (Collection des Études Augustiniennes. Série Moyen Âge et Temps Modernes, 31).

Burghart à paraître $=$ M. Burghart, Sermons of distinction: A vindication of the study of distinctiones collections, dans The same and different: Strategies of retelling the bible wit-
- Expl. : ... in illo simbolo sunt principalia fidei ut prius dictum est.

- fol. 309v(307v)-313 blancs (mais numérotés) au moment de la reproduction photographique, les deux derniers folios blancs ont été retirés ensuite. hin the "new communities of interpretation" (1350-1570), Turnhout, à paraître.

Caplan 1934-36 = H. Caplan, Mediaeval artes praedicandi, New York, 1934-1936.

Charland $1936=$ Th.-M. Charland, Artes praedicandi. Contribution à l'histoire de la rhétorique au Moyen Âge, Paris-Ottawa, 1936 (Publications de l'Institut d'Études Médiévales d'Ottowa, VII).

Châtillon 1964 = F. Châtillon, Vocabulaire et prosodie $d u$ distique attribué à Augustin de Dacie sur les quatre sens de l'Écriture, dans L'homme devant Dieu : mélanges offerts au Père Henri de Lubac, vol. 2, Paris, 1964, p. 17-28.

De Lubac 1959 = Henri de Lubac, Exégèse médiévale. Les quatre sens de l'Écriture, Paris, 1959.

García Y García 1982 = A. García Y García, Glosas de Juan Teutónico, Vicente Hispano y Dámaso Húngaro a los Arbores Consanguinitatis et Affinitatis, dans Zeitschrift der SavignyStiftung für Rechtsgeschichte / Kanonistische Abteilung, 681, 1982, p. 153-185.

Gehrt 2005 = W. Gehrt, Die Handschriften der Staats- und Stadtbibliothek Augsburg $4^{\circ}$ Cod 151-304, Wiesbaden, 2005.

Giermann - Härtel - Arnold 1993= R. Giermann, H. Härtel, M. Arnold, Handschriften der Dombibliothek zu Hildesheim, vol. 2, Wiesbaden, 1993.

Glorieux 1971 = P. Glorieux, La faculté des arts et des maîtres au XIII siècle, Paris, 1971.

Hain 1826-38 = L. Hain, Repertorium bibliographicum, Stuttgart-Tübingen, 1826-38.

Hilg 2007 = H. Hilg, Lateinische mittelalterliche Handschriften in Quarto der Universitätsbibliothek Augsburg die Signaturengruppen Cod. I.2.4 und Cod. II.1.4, Wiesbaden, 2007.

Hödl - Koch 1999 = L. Hödl,W. Koch, Repertorium der lateinischen Sermones des Spätmittelalters 1350 bis 1500, Münster, 1999 [CD-ROM].

Klein-Ilbeck \& Ott 2009= B. Klein-Ilbeck et J. Ott, Die Handschriften der Thüringer Universitäts- und Landesbibliothek Jena, vol. 2: Die mittelalterlichen lateinischen Handschriften der Signaturreihen außerhalb der Electoralis-Gruppe, Wiesbaden, 2009.

Lacombe $1927=$ G. Lacombe, Prepositini cancellarii 
Parisiensis 1206-1210 opera omnia. 1 : La Vie et les oeuvres de Prévostin, Kain, 1927 (Bibliothèque thomiste, 11).

Lawell 2009 = D. Lawell, Spectacula contemplationis (12441246) : A Treatise by Thomas Gallus, dans Recherches de Théologie et Philosophie médiévales 76-2, 2009, p. 249285.

Lerner $1976=$ R.E. Lerner, Refreshment of the saints: the time after Antichrist as a station for earthly progress in medieval thought, dans Traditio, 32, 1976, p. 97-144.

Madre 1965 = A. Madre, Nikolaus von Dinkelsbühl, Leben und Schriften, Band XL Heft 4, Münster, 1965

Metzger 2017 = S.M. Metzger, Gerard of Abbeville, Secular Master, on Knowledge, Wisdom and Contemplation, vol. 1, Leiden, 2017.

Miedema 1996 = N.R. Miedema, Die «Mirabilia Romae». Untersuchungen zu ihrer Überlieferung mit Edition der deutschen und niederländischen Texte, Tübingen, 1996, 588 p. (Münchener Texte und Untersuchungen zur deutschen Literatur des Mittelalters, 108).

Moore 1936= Philip S. Moore, The Works of Peter of Poitiers, Master in Theology and Chancellor of Paris (1193-1205), Notre Dame (Indiana), 1936.

Quinto 1989 = R. Quinto, Timor reverentialis nella lingua, dans Archivum latinitatis medii aevi, 48/49 (1988-89), p. 103-143.

Rossmann $1983=\mathrm{H}$. Rossmann, Keck, Johannes, Die deutsche Literatur des Mittelalters. Verfasserlexikon, IV, $2^{\mathrm{e}}$ édition, Berlin-New York, 1983, col. 1090-1104.

Schneyer $1967=$ J .B. Schneyer, Sind die Sermonessamlung des Robert de Sorbono Praedigtskizzen Alberts d. Gr. aufgenommen? Auf der Suche nach der Ergänzung zur
Handschrift Leipzig, Univ. 683, dans Recherches de théologie ancienne et médiévale, , 1967, p. 179-218.

Schneyer $1969-90=$ J. B. Schneyer, Repertorium der lateinischen Sermones des Mittelalters für die Zeit von 11501350, 11 vol. , Münster i.W., 1969-90 (Beiträge zur Geschichte der Philosophie und Theologie des Mittelalters, 43/1-11).

Stegmüller 1950-80 = F. Stegmüller, Repertorium Biblicum Medii Aevi, 11 vol. , Madrid, 1950-1980.

Swainson $1875=\mathrm{Ch}$. A. Swainson, The Nicene and Apostles' creeds : their literary history: together with an account of the growth and reception of the sermon on the faith, commonly called "The Creed of St. Athanasius», Londdres, 1875.

Théry $1934=$ G. Théry, Thomas Gallus et Egide d'Assise. Le traité De septem gradibus contemplationis, dans Revue néoscolastique de philosophie, 36, 1934, p. 180-190.

Thorndike $1955=$ L. Thorndike, Unde Versus, dans Traditio 11 (1955), p. 179-80, 163-93.

Thorndike $1958=$ L. Thorndike, De Complexionibus, dans Isis 49 :4 (1958), p. 398-408.

Vollmann $2007=$ B.K. Vollmann, Schlitpacher, dans Otto zu Stolberg-Wernigerode (dir.), Neue deutsche Biographie, vol. 23, Berlin, 2007, p. 83-94.

Walther 1963-69 = Hans Walther, Proverbia sententiaeque latinitatis medii aevi. Lateinische Sprichwörter und Sentenzen des Mittelalters in alphabetischer Anordnung, Carmina medii aevi posterioris latina, vol. 1-6, Göttingen, 1963-69.

Wenzel 2015 = S. Wenzel, Medieval artes praedicandi: $a$ synthesis of scholastic sermon structure, Toronto, 2015. 